\title{
International trade, development traps, and the core-periphery structure of income inequality
}

\author{
Dominik Hartmann $^{\mathrm{a}, \mathrm{b}, \mathrm{c}, *}$, Mayra Bezerra ${ }^{\mathrm{b}}$, Beatrice Lodolo ${ }^{\mathrm{c}}$, Flávio L. Pinheiro ${ }^{\mathrm{d}}$ \\ ${ }^{a}$ Department of Economics and International Relations, Federal University of Santa Catarina, R. Eng. Agronômico Andrei Cristian Ferreira, s/n - \\ Trindade, Florianópolis - SC, 88040-900, Brazil \\ ${ }^{\mathrm{b}}$ Fraunhofer Center for International Management and Knowledge Economy, Neumarkt 9, 04109 Leipzig, Germany \\ ${ }^{\mathrm{c}}$ Department of Innovation Economics, University of Hohenheim, Wollgrasweg 23, 70593 Stuttgart, Germany \\ ${ }^{\mathrm{d}}$ Nova Information Management School (NOVA IMS), Universidade Nova de Lisboa, Campus de Campolide, 1070-312 Lisboa, Portugal
}

Received 29 July 2018; accepted 24 September 2019

\begin{abstract}
Research on economic complexity has shown that a country's type of exports conditions its future path of economic diversification and economic growth. Yet little emphasis has been put on the inequality associated with the types of products traded between countries and different regions of the world. Here we analyze the income inequality associated with the imports and exports of 116 countries in the period from 1970 to 2010 . Our analysis shows that methods from network science and visual complexity research can help to reevaluate old theories in economics, such as core-periphery structures in international trade or structural development traps. Our results illustrate that the core-periphery structure of global trade affects not only the income inequality between countries, but also the income inequality within countries. Moreover, they reveal the structural constraints that developing and emerging economies face in promoting inclusive growth and benchmark their productive transformations with cases of successful catching up and developed economies. The results show that countries, such as South Korea or Germany, have benefited from outsourcing high inequality products. In contrast, some middle-income countries, such as Brazil or South Africa, face structural development constraints consisting of a large average distance of their export products to low inequality products and a "gravitational force" towards high inequality products. Finally, developing economies, such as Nicaragua or Sri Lanka face a double development trap for inclusive growth, as their economies depend on both a large share of high inequality exports and imports.
\end{abstract}

Keywords: Trade; Inequality; Economic complexity; Development trap

(C) 2019 The Authors. Production and hosting by Elsevier B.V. on behalf of National Association of Postgraduate Centers in Economics, ANPEC. This is an open access article under the CC BY-NC-ND license (http://creativecommons. org/licenses/by-nc-nd/4.0/).

\section{Introduction}

The positive and negative effects of globalization and international trade are at the center of heated debates in economics. While one side points to the positive effects of international trade on knowledge diffusion, productive efficiency, economic growth and global welfare, the other side highlights the negative effects of international trade

\footnotetext{
* Corresponding author.

E-mail address: dominik.hartmann@ufsc.br (D. Hartmann).
} 
on income inequality between and within countries (Singer, 1950; Prebisch, 1962; Krueger, 1985; Proudman and Redding, 2000; Srinivasan and Bhagwati, 2001; Stiglitz, 2002; Cimoli et al., 2015). It is no secret that during the process of economic development, developed economies, such as Germany or South Korea, have outsourced less desirable productive activities, such as simple textile products, and focused instead on more value-added and sophisticated product, such as cars or computer parts. In contrast, many developing and emerging economies have tended to focus on the export of simple products, such as fruits, textiles, or mining products, that are often associated with low labor costs, exploitation of natural resources and high levels of inequality (Engerman and Sokoloff, 1997; Hartmann et al., 2017).

Both companies and consumers in developed economies benefit from the lower prices of the inputs produced in countries with lower labor costs and weaker labor laws (Frobel et al., 1976; Baldwin, 2008). Not surprisingly the exploitation of workers in developing countries in supplying inputs for richer industrialized economies has been sharply criticized (Charnovitz, 1987; Martin and Maskus, 2001). But developing economies may also gain from making the first steps towards industrialization steps by simple manufactures, such as textiles. Moreover, it must also be mentioned that a large share of the imports of developed economies are not exploitative products from developing countries, but rather complex products, such as cars, specialized machine tools, and medical equipment, that are associated with lower levels of inequality in the countries producing them. Thus, an evaluation that developed economies are prosperous because they exploit poor economies does not seem to be the full story.

What is clear is that trade seems to have a significant effect on income inequality. Most studies in trade and development economics, though, have focused more on the effects of international trade pattern on economic growth and the income differences between countries than on the effects on international trade on income differences within countries. Recent research has shown that the economic catch-up and leapfrogging ahead processes in several Asian economies had a significant effect on job losses of the middle class in developed economies (Milanovic, 2011; Autor et al., 2013). Yet, a more comprehensive picture of the effects of global trade on the income inequality in developing, emerging and developed economies is missing. Arguably, new methods from complexity research (Hidalgo et al., 2007; Hausmann et al., 2014; Hartmann et al., 2017) can contribute to the challenge of disentangling the complex relationships between global trade networks and income inequality.

Here, we use methods from economic complexity research to analyze the income inequality associated with the export and import portfolio of 116 countries and their bilateral trade between 1970 and 2010. The application of methods from network science and complexity research helps us reevaluate ideas on core-periphery structures of trade (Prebisch, 1962; Wallerstein, 2004) and to illustrate the income inequality associated with countries' trade specialization and partners. Moreover, these methods help to reveal how successful catching-up economies have changed their trade portfolio to promote inclusive growth and quantify the structural development traps faced by developing and middleincome countries (Felipe et al., 2012a,b; Jankowska et al., 2012; Lee, 2013). The remainder of this paper is structured as follows. Section 2 provides a literature brief on core-periphery structures of trade, economic complexity and income inequality. Section 3 introduces the data and methods. Section 4 presents the results. Section 5 provides concluding remarks.

\section{Literature review}

The need of developing countries to diversify and sophisticate their productive structures, and the role of the embeddedness of international trade networks for their economic diversification processes, has been extensively discussed in development economics and politics (Rosenstein-Rodan, 1943; Furtado, 1959; Fajnzylber, 1990; Hausmann et al., 2014; Cimoli et al., 2009, 2015).

Several researchers have argued that developing economies are poor due to their trade specialization and embeddedness in the global trade system, in which rich countries from the center of the world economy focus on a varied set of knowledge-intensive and value-added products, whereas developing economies from the periphery of the world economy specialize in simple, resource and labor exploiting products (Prebisch, 1962; Wallerstein, 2004; Cimoli and Katz, 2003; Cimoli et al., 2015; Gala et al., 2017). Of particular interest for theories on global center-periphery structure has been the Prebisch-Singer hypothesis, arguing that the price of primary products decreases relative to the price of manufactured products in the long run because those manufactured goods have a higher income elasticity of demand than primary products (Singer, 1950; Prebisch, 1962). Thus with increasing income, the demand for manufactured goods rises more sharply than the demand for primary commodities. This mechanism undermines economic growth in 
the periphery of the world economy and results in the persistence and increase of income inequality across countries from the center and the periphery of the world economy. In a similar vein, Wallerstein (2004) also argued that the structures of the global market are accountable for global inequality. The world system redistributes surplus value from the periphery (i.e., poor primary goods-based countries) to the core (rich industrialized economies), allowing the perpetration of the exploitation of the former by the latter. To overcome this underdevelopment mechanism and reduce their foreign dependency on industrialized imports, several Latin American and African economies introduced highly protectionist trade policies in the 1960s to 1970s. The inward oriented model of import substitution industrialization favored state-driven economic diversification through high taxes on imports, nationalization, and subsidization of key industries. This model had some (initial) success in economies with a relatively large internal market, such as Brazil or Argentina, yet most economies ended up with severe inefficiencies and a profound economic crises in the 1980s (Krueger, 1985).

It must be noted that when engaging in the international trade of more complex products, countries have the opportunity to enhance their pool of collective knowledge and efficiency by being part of a bigger knowledge society (Stiglitz et al., 2014) which can have a positive impact on the quality of a country's exports and economic development in the long run (Gereffi, 1999; Bathelt et al., 2004; Macgarvie, 2006). Most developed economies not only import low value-added products from developing economies, but also import and learn from a large share of sophisticated products. Modern global value chains can greatly increase the knowledge, efficiency, and quality of sophisticated products, such as cars, smartphones or airplanes. Inwards-looking, protectionist international trade policies were for many years harmful to the development process of several developing economies and disconnected them from global knowledge flows. While the emergence of industrial parks has been observed all across the world, many developing economies, e.g. in Latin America, Africa, and Asia are still mainly exporting simple products associated with cheap labor and resource richness, and import complex manufacturing and chemical products without engaging in learning by interacting (Hartmann et al., 2016). Many of these countries find themselves in a development trap because they are not able to enhance their pool of collective knowledge due to the lack of appropriate institutions and industrial policies promoting both internal and external learning (Stiglitz et al., 2014).

In contrast to the inwards-looking and mainly state-driven "import substitution industrialization" strategy of several Latin American economies, several East Asian economies have chosen an export-led strategy, in which they combined both state and market forces to promote local and international learning, resulting in the diversification of their economies into more value-added and complex products (Wade, 1990; Amsden, 1992; Stiglitz, 1996). Several countries, such as South Korea or Singapore, have not only caught up, but also leapfrogged ahead into more complex products associated with higher wages and lower levels of inequality (Hartmann et al., 2016). These countries have also been more successful in overcoming the middle-income trap, than for instance Brazil, South Africa, or Indonesia (Amsden, 1992; Jankowska et al., 2012; Felipe et al., 2012a; Lee, 2013). These East Asian economies quickly upgraded their infrastructure, established high-quality education system, and diversified into complex industries. In contrast, Brazil and South Africa, which have exploited their natural advantages, suffer from low investment, limited economic diversification, and poor labor market conditions. They have not yet been able to move their resource-driven economies driven by cheap labor and natural abundance, towards a more knowledge-driven and inclusive economies, based on interactive learning and prolific policy co-ordination in the areas of education, infrastructure, innovation and financing (Rhee, 2012; Jankowska et al., 2012; Lee, 2013).

Recently, a consensus has emerged in development economics, that in order to catch-up and leapfrog ahead, developing countries may need to (1) overcome both market and government failures, (2) establish learning institutions by linking industry, state, science and the civil society and facilitating both endogenous innovation and external learning, and (3) promote smart diversification strategies (Freeman, 1987; Rodrik, 2004; Hartmann, 2014; Hartmann et al., 2018).

\subsection{Smart diversification policies, economic complexity, and inclusive growth}

Smart economic diversification strategies consider the feasibility and desirability of different products or technologies for each country and/or region (Hartmann et al., 2018; Balland et al., 2018). Moreover, successful diversification strategies require countries to jump towards products at the right stage in their development (Alshamsi et al., 2018). Diversification strategies are very likely to fail when a country aims to jump too far away into completely unrelated activities, especially at the wrong moment. (Hidalgo et al., 2007; Pinheiro et al., 2018; Alshamsi et al., 
2018). Jumping too close or into the wrong products can hamper the long-run economic development prospects. For instance, mere emphasis on natural resources, such as crude petroleum, may generate income, but can undermine long-run economic development and lead to high levels of income inequality in a country (Hartmann et al., 2017). New methods of economic complexity research help to both identify the feasibility and desirability of different product options, by taking a country's structural constraints and opportunities into account (Hartmann et al., 2018).

In a seminal paper, Hidalgo et al. (2007) combined methods from economics and complexity research to show that usually countries are not able to randomly jump from one type of product to another, but their path of economic diversification is strongly conditioned by the positioning of their exports in the product space. The product space is a network estimating the relatedness/closeness of hundreds of different export products. It estimates the shared productive capabilities required to produce two different trade products based on the conditional probability that two products are co-exported (Hidalgo et al., 2007; Hausmann et al., 2014). The core-periphery structure of the product space also implies that countries exporting only products in the periphery of the product space, such as such as cocoa beans, copper, or crude petroleum, may find themselves in a development trap that consists of a great distance from more central areas of the product space, in which more complex products, such as cars, medicine or robots are positioned (Hidalgo et al., 2007; Jankowska et al., 2012). Subsequent research has also shown that only a small percentage of countries' diversification jumps are unrelated, i.e. into more distant parts of the product space, and these unrelated variety jumps typically occur at intermediate levels of economic development and relatively high levels of human capital (Pinheiro et al., 2018). This difficulty of moving into unrelated and complex products is a severe problem for countries that are dependent on primary products, such as Saudi Arabia, Iran or South Africa. There is also strong empirical evidence that countries exporting complex products tend to have a significantly higher level of GDP per capita and economic growth outlook than countries that produce simple or resource-based products in the periphery of the product space (Hidalgo and Hausmann, 2009; Felipe et al., 2012a,b; Cristelli et al., 2013; Hausmann et al., 2014).

However, the type of products that countries exports not only conditions their total income, but also the distribution of income within the countries. Recent research has shown that countries exporting complex products have a significantly lower level of income inequality than countries exporting simple products (Hartmann et al., 2017). There are several reasons for this. Diversified and complex productive structures require more inclusive institutions with better educated, well paid and empowered workers (Engerman and Sokoloff, 1997; Acemoglu and Robinson, 2012; Hartmann, 2014; Hartmann et al., 2017). Workers in a diversified economy tend to have a wider range of job choices, tend to form more efficient unions, and thus tend to have more bargaining power. For instance, a hypothetical coffee company in an economy that is almost exclusively exporting coffee is probably able to pay simple workers lower salaries than if the same coffee company would be located in an economy with multiple different industries. Moreover, it is arguably harder to force a high-skilled employee in a pharmaceutical industry to work in exploitative conditions and achieve a low salary, than to force a low-skilled employed in a simple agricultural activity. Finally, a complex economy is likely to be associated with a better distribution of political and economic power (Collier, 2007; Hartmann et al., 2017).

Moreover, recent research has estimated the level of income inequality associated with different types of goods, such as crude petroleum, coffee beans or machines (Hartmann et al., 2017). The Product Gini Index (PGI) proxies the level of income inequality associated with different 775 different types of export goods. Formally, the PGI is defined as the average level of income inequality of a product's exporters, weighted by the importance of each product in a country's export basket. Among the products associated with high levels of inequality are simple agricultural products, such as cocoa beans or cotton, as well as mining products, such as copper, zinc or nickel. Among the products associated with low inequality, feature more complex, knowledge-based activities, such as medicaments, hormones or X-Ray machines, or specialized machinery. The PGIs have been used to compare structural constraints of income inequality in Latin America and High Performing Asian Economies (HPAE) and design smart strategies for economic diversification and inclusive growth (Hartmann et al., 2016, 2018). These studies showed that Latin American economies have a significantly higher XGini index — an index measuring the average PGI values associated with a country's export portfolio- than HPAE (Hartmann et al., 2016). Nonetheless developing economies, such as e.g. Paraguay, do have opportunities to reduce their dependency on simple exports and move into related, lower PGI and higher complexity products (Hartmann et al., 2018). 


\subsection{Literature gap regarding the PGIs associated with the bilateral trade between countries and geographic regions}

New approaches from economic complexity research have helped to obtain a more detailed "fingerprint" of the productive structure of economies, and a better understanding of the effect of productive diversification and sophistication on economic growth and income inequality. Yet little emphasis has been put on using these new methods to analyze the inequality associated with the mutual trade between countries or different continents / economic regions. I order to address this gap, here we analyze the income inequality associated with both the export and import portfolios of 116 countries between 1970 and 2015. This helps us to reveal the core-periphery structure of income inequality associated with global trade. Moreover, we create a global ranking of Export Gini (XGini) and Import Gini (ImpGini) of the 116 countries and analyze their evolution between 1970 and 2015. Finally, we measure the average distance of countries' export portfolio to low PGI products. This allows us to reveal the structural development trap that countries face at a medium stage of economic development.

\section{Data and methods}

Data on income inequality comes from the Galbraith et al., 2014 (GINI EHII dataset). Data on international trade comes from the MIT's Observatory of Economic Complexity (atlas.media.mit.edu). Concerning the trade data, we use the Standard International Trade Classification SITC-4 rev 2, since it provides an extended time series from 1962 to 2014. This dataset combines exports data from 1962 to 2000, compiled by Feenstra et al. (2005), and data from the U.N. Comtrade for the period between 2001 and 2010. In line with Pinheiro et al. (2018), we reduce noise coming from underreporting and from variations in the size of the economies of countries and products by discarding all countries with a population of lower than 1.2 million citizens, a total trade below USD 1 billion in 2008. Moreover, we exclude products for which all yearly trade flows were valued at less than 5,000 USD and all products with exports value equal to zero for more than $80 \%$ of the countries. Additionally, products with a global export of less than USD 10 million and countries whose exports equal to zero for $95 \%$ of the products are also excluded. After applying these filters, our final sample consists of 116 countries, representing $97.45 \%$ of global GDP and $86.67 \%$ of global trade in 2008 .

Data on economic complexity comes from the Observatory of Economic Complexity (atlas.media.mit.edu). The Economic Complexity Index measures the diversity and sophistication of the productive structure of a country, and thus also the knowledge embedded in an economy, by considering both the diversity and the ubiquity of the products that a country exports (Hidalgo and Hausmann, 2009; Hausmann et al., 2014). The advantage is that this index not only considers the aggregate level of production, such as GDP per capita, or the number and balance of products, such as variety or entropy measures, but also how many countries are able to export a particular product. For instance, while many countries are able to export fish, only a relatively limited number of countries are able to export X-Ray machines.

We make use of the Product Space to estimate the relatedness between different types of export products (Hidalgo et al., 2007; Hausmann et al., 2014) and the Product Gini Index (Hartmann et al., 2017) to reveal the level of inequality associated with different parts of the product space.

The product space estimates the level of shared productive capabilities between two products, based on the conditional probability that countries export both products with a revealed comparative advantage (Hidalgo et al., 2007).

$$
\phi_{p p^{\prime}}=\frac{\sum_{c} M_{c p} M_{c p^{\prime}}}{\max \left(k_{p}, k_{p^{\prime}}\right)}
$$

where $\phi_{p p^{\prime}}$ measures the proximity between two products $p$ and $p^{\prime}$ in the product space the $c$ and the matrix $M_{c p}$ is 1 if a country $c$ has a revealed comparative advantage in product $p$ and is 0 otherwise.

The product space allows us to estimate the entry likelihood of new products, according to the density of comparative advantages in products that are related to this potential new product. For this purpose, we measure the density $\omega$ of products with revealed comparative advantages around product $p$ in the product basket of country $c$.

$$
\omega_{c p}=\frac{\sum_{p^{\prime}} M_{c p^{\prime}} \phi_{p p^{\prime}}}{\sum_{p^{\prime}} \phi_{p p^{\prime}}}
$$


The Product Ginis (PGI) we calculate in line with Hartmann et al. (2016, 2017). The Product Gini Index (PGI) is defined as the average level of income inequality of a product's exporters, weighted by the importance of each product in a country's export basket. The $P G I$ of product $p$ is calculated as:

$$
P G I_{p}=\frac{1}{N_{p}} \sum_{p} M_{c p} S_{c p} \text { Gini }_{c}
$$

where $\operatorname{Gini}_{c}$ is the Gini coefficient of country $c, M_{c p}$ is 1 if country $c$ exports product $p$ with revealed comparative advantage (RCA) (Balassa, 1965) and 0 otherwise, $s_{c p}$ is the share of country $c$ 's exports represented by product $p . N_{p}$ is a normalizing factor that ensures PGIs are the weighted average of the Ginis. $N_{p}$ and $s_{c p}$ are calculated as:

$$
\begin{aligned}
& S_{c p}=\frac{X_{c p}}{\sum_{p^{\prime}} X_{c p^{\prime}}} \\
& N_{p}=\sum_{c} M_{c p} S_{c p}
\end{aligned}
$$

where $X_{c p}$ is the total export of product $p$ by country $c$.

Agricultural, textile and mining products, such as cocoa beans, cotton, tin, or petroleum gases, feature among the products with the highest PGI products (see Table 1). Among the products with the lowest PGI values are manufacturing and chemical products, such as analog instruments, miscellaneous pharmaceutical products, heating and cooling equipment, or papermaking machine parts.

We use the PGI values to calculate the income inequality associated with the import and export portfolio of countries. The Export Gini (XGini) is defined as the average PGI of the products present in a country's export portfolio, the Import Gini (ImpGini) as the average PGI of the country's import portfolio. The XGini and ImpGini of country $c$ are calculated as:

$$
\begin{aligned}
& \text { XGini }_{\mathrm{c}}=\frac{1}{N_{c}} \sum_{p} M_{c p} S_{c p} P G I_{p} \\
& N_{c}=\sum_{p} M_{c p} S_{c p} \\
& \operatorname{ImpGini}_{c}=\frac{1}{\sim N_{c}} \sum_{p} \sim M_{c p} \sim S_{c p} P G I_{p} \\
& \sim N_{c}=\sum_{p} \sim N_{c p} \sim S_{c p}
\end{aligned}
$$

where $S_{c p}\left(\sim S_{c p}\right)$ is the share of product $p$ in the country's $c$ export (imports) to a set of different countries, $M_{c p}$ $\left(\sim M_{c p}\right)$ is 1 if product $p$ is produced (imported) by country $c$ with revealed comparative advantage and 0 otherwise, and $N_{c}\left(\sim N_{c}\right)$ is a normalizing factor to ensure that the XGini (ImpGini) is a weighted average of the PGI.

Moreover, we not only analyze the average PGI values of the export of a country to the world (such as e.g. in Hartmann et al., 2016), but also the imports and relationships with single countries or different geographic regions of the World, such as East Asia, Sub-Saharian Africa or Southern Europe. A list of countries belonging to each geographic region can be found in Table A1 of the Appendix

Finally, we deliberately use methods from visual complexity research and data visualization in this article (Hidalgo et al., 2007; Simoes and Hidalgo, 2011; Guevara et al. 2016). For instance, colored trade matrices, temporal ranking graphs, and product space visualizations can help to reveal the complex association between trade and inequality.

\section{Results}

\subsection{The core-periphery structures of income inequality in the global trade network}

We start our analysis by estimating the income inequality associated with the imports and exports between countries. The Product Gini Index (PGI) trade matrix illustrates the average PGIs of the exports and imports of 116 countries in 
Table 1

Top and bottom 15 products in the PGI ranking between 2000 and 2008.

\begin{tabular}{llll}
\hline 15 Products with highest PGIS & & \\
\cline { 1 - 2 } Rank & SITC_ID & SITC product & 0.525 \\
766 & 721 & Cocoa Beans & 0.520 \\
765 & 2654 & Agave Fibers & 0.515 \\
764 & 6545 & Jute Woven Fabrics & 0.512 \\
763 & 2640 & Jute & 0.506 \\
762 & 4245 & Castor Oil & 0.506 \\
761 & 6871 & Unwrought Tin and Alloys & 0.505 \\
760 & 4314 & Waxes & 0.505 \\
759 & 5622 & Phosphatic Fertilizers & 0.503 \\
758 & 6592 & Knotted Carpets & 0.503 \\
757 & 1213 & Tobacco Refuse & 0.502 \\
756 & 2876 & Tin & 0.502 \\
755 & 3413 & Liquified Petroleum Gases & 0.502 \\
754 & 6521 & Unbleached Cotton Woven Fabrics & 0.501 \\
753 & 5222 & Inorganic Acids and Oxygen Compounds & 0.501
\end{tabular}

15 Proudcts with lowest PGIS

\begin{tabular}{llll}
\hline Rank & SITC_ID & SITC product & PGI \\
\hline 15 & 7373 & Miscellaneous Metalworking Machinery & 0.357 \\
14 & 8744 & Analog Instruments for Physical Analysis & 0.357 \\
13 & 8996 & Orthopedic Devices & 0.357 \\
12 & 5419 & Non-Medicinal Pharmaceutical Products & 0.357 \\
11 & 7416 & Miscellaneous Heating and Cooling Equipment & 0.356 \\
10 & 7452 & Miscellaneous Non-Electrical Machines & 0.355 \\
9 & 121 & Miscellaneous Animal Entrails & 0.353 \\
8 & 5838 & Polymerization Ion Exchangers & 0.353 \\
7 & 7449 & Miscellaneous Parts of Lifting Machinery & 0.352 \\
6 & 8851 & Watches & 0.352 \\
5 & 7233 & Road Rollers & 0.346 \\
4 & 6412 & Rolls of Paper & 0.345 \\
3 & 5415 & Hormones & 0.342 \\
2 & 7251 & Cellulose Pulp Making Machines & 0.339 \\
1 & 7259 & Paper Making Machine Parts & 0.337 \\
\hline
\end{tabular}

2010 (see Fig. 1). High average PGI values are colored red, while low average PGI values are blue. It can be observed that the bilateral XGini and ImpGinis - i.e., the weighted average PGI associated with the exports to a country (or imports from a country) - varies across countries, geographic regions, and trade partners. Moreover, they are not necessarily reciprocal between trade partners. For instance, highly developed economies, such as Germany, Sweden or South Korea mainly exchange low PGI products with each other but import products with higher PGI values from developing economies. The PGI trade matrix illustrates a clear core-periphery structure, between different geographic regions, consisting in a periphery exporting products with high levels of inequality associated with them, and a core exporting products with low average PGI values (see also Appendix A1 for an aggregation by geographic region). Additionally, the total trade volume between the core countries of the world economy is significantly larger than the trade among the countries from the periphery, and the trade between the core and the periphery (see Appendix Figure A2).

The PGI bilateral trade matrix helps in understanding which geographic regions of the world form part of the core and the periphery of the world economy and how this positioning in the global trade network is associated with income inequality in the respective countries. (A full list of the countries belonging to each geographic region can be found in Table A1 of the Appendix). European, East Asian and North American economies mainly export low PGI products to the rest of the world and import high PGI products from developing countries in Africa, Latin America, and Central, 

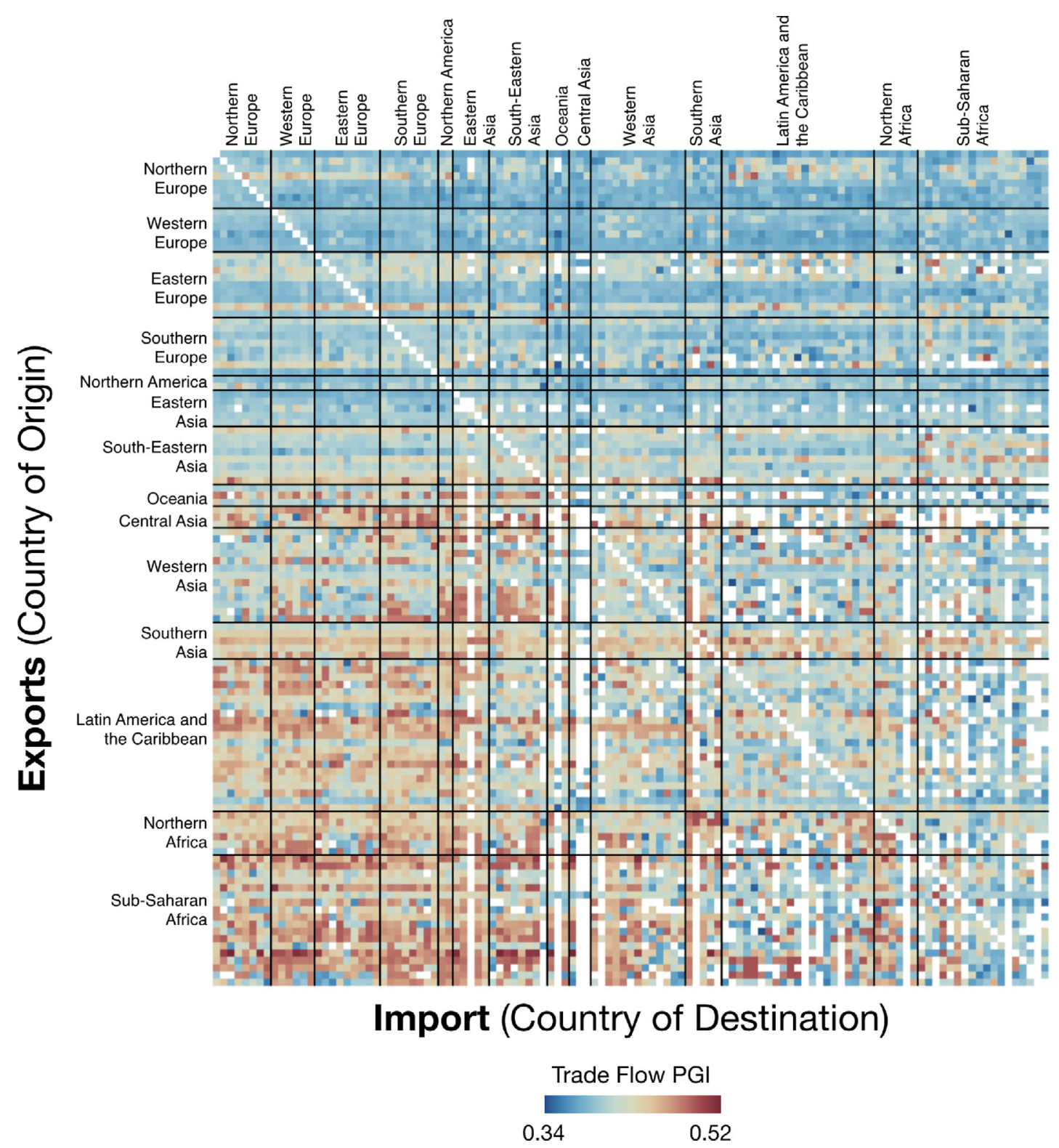

Fig. 1. The Product Gini Index (PGI) trade matrix in 2010. Each row depicts the exports of one country to the other 115 countries, each column the imports of a country from the other 115 countries. The fields are colored according to their PGI values; high average PGI values are colored red, low average PGI values blue, white fields indicate no significant exports/imports between these countries.

Western and Southern Asia. Interestingly, African, Latin American and Western Asian economies export relatively lower PGI products to each other, in comparison to their trade flows with Europe. However, the amount of these trade flows is significantly lower than the trade flows of these economies with European, East Asian or North American economies. Moreover, it is noteworthy that the largest share of the trade of European economies is among each other and consists of low PGI products (see also Fig. A2 in the Appendix).

Our results confirm the findings of previous studies on the core-periphery structure of the global trade system (Prebisch, 1962; Wallerstein, 2004). Yet, the PGI values also allow us to reveal the types of products and the level of inequality associated with these products. It becomes evident that the core of the world economy does not only produce and export more sophisticated products and thus is richer than the periphery of the world economy (Gala et al., 2017), but it also exports products associated with lower levels of income inequality. Thus, the core-periphery structure of 
a)

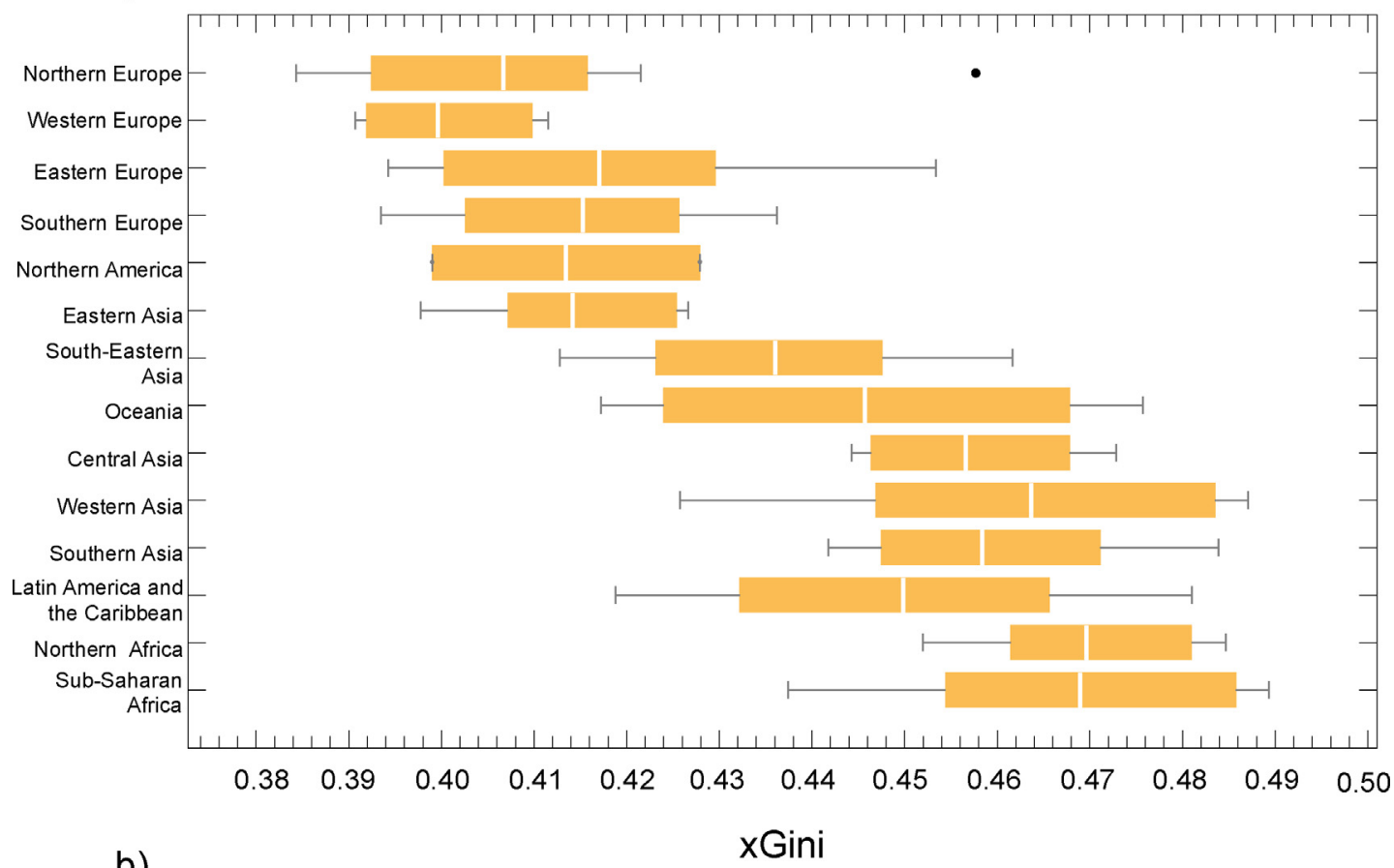

b)

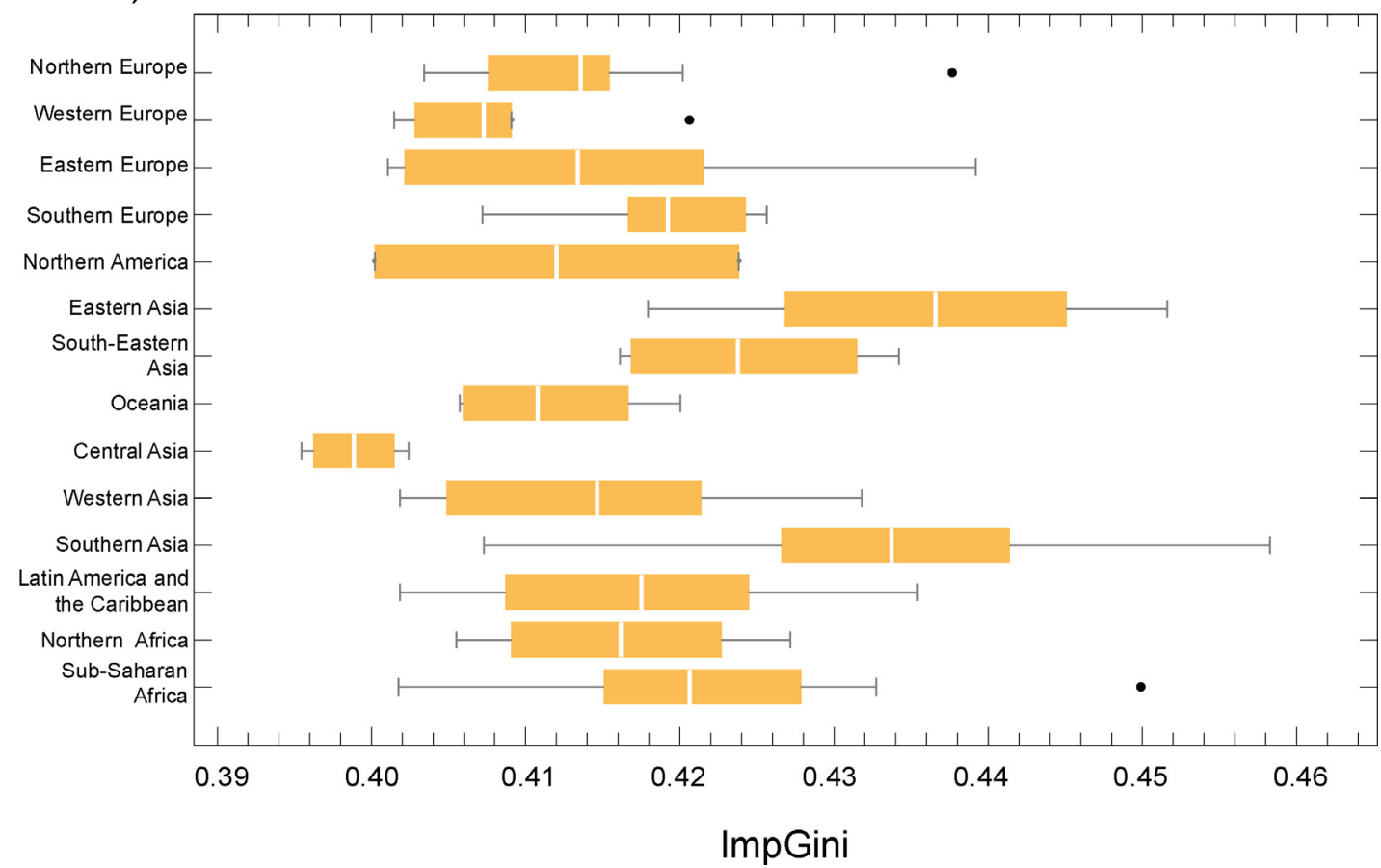

Fig. 2. Boxplots on the (a) XGinis and (b) ImpGinis of countries and regions in 2010. 


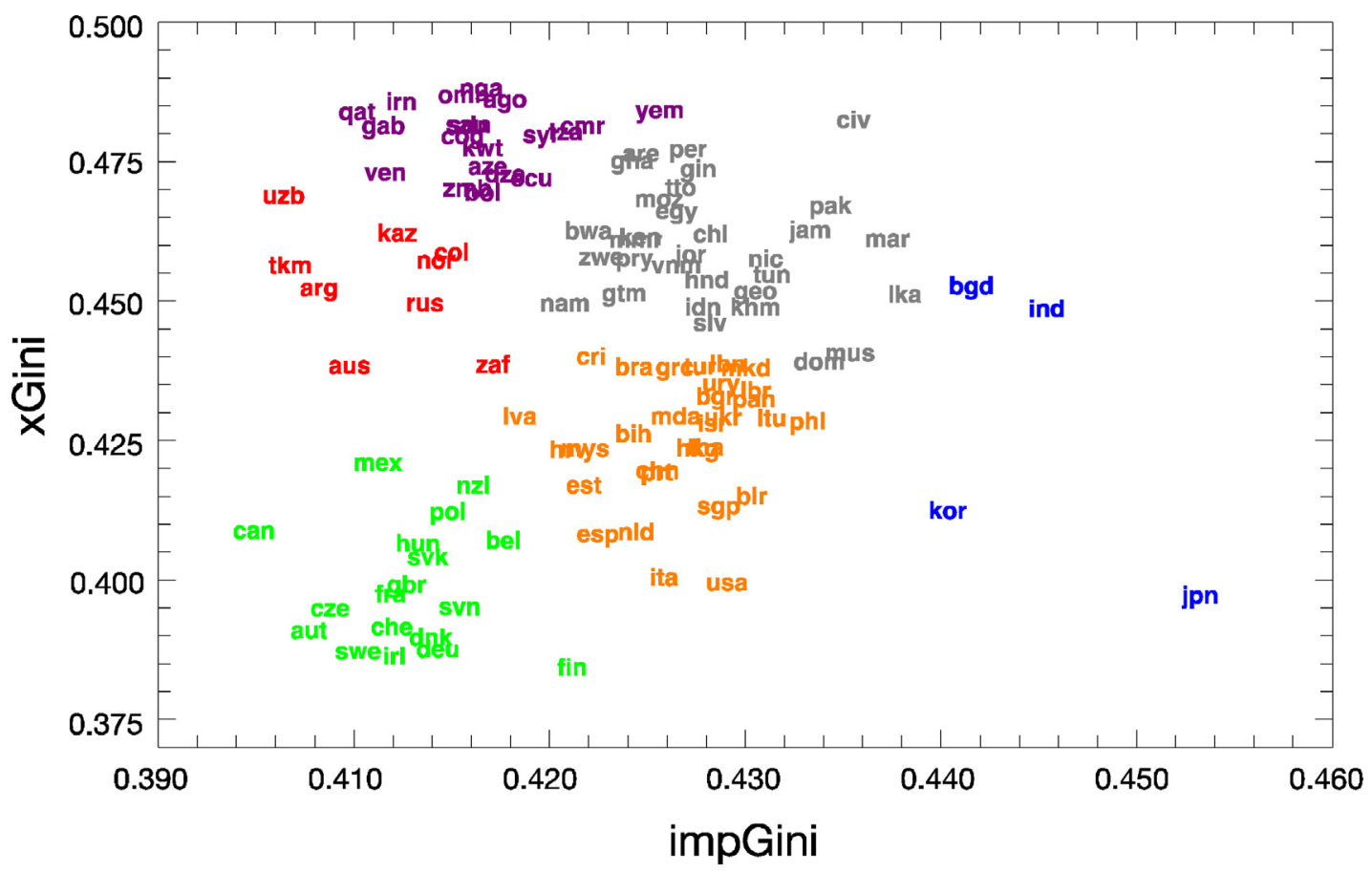

Fig. 3. XGini and ImpGini clusters in the time period 1990-2010. Countries are colored according to 6 clusters identified by the K-means algorithm. The XGini and ImpGini values of each country correspond to the average of their yearly values between 1990 and 2010.

global trade is arguably not only associated with income inequality between countries, but also with income inequality within countries.

\subsection{Differences in XGinis and ImpGinis across geographic regions and countries}

In this section, we first analyze the boxplots of the XGini and ImpGini values of the different economic regions and then cluster countries according to their XGini and ImpGini values.

Fig. 2(a) illustrates that Western and Northern European economies, followed by Southern European, North American and East Asian economies, have the lowest XGinis, and thus lowest levels of income inequality associated with their export portfolios (see Fig. 2a). These (relatively) low levels of XGINI help to promote inclusive growth. In contrast, African economies, followed by Central, Western and Southern Asian economies have the highest XGini values, and thus their productive structures and export portfolio imposes strong constraints on their ability to reduce income inequality.

The differences in the ImpGinis between the geographic regions are significantly less pronounced (see Fig. 2b). This is the case because the import portfolios of the most countries are much more similar than their export portfolios. Still, there are noteworthy differences and outliers. For instance, Central Asian economies, such as Kazakhstan, Turkmenistan, or Uzbekistan, have a significantly lower ImpGini than most other regions. The reason for this is that they import a large amount of manufactured, intermediate to low PGI products, such as valves, iron pipes, or air pumps that are necessary for the extraction and distribution of their main export products, such as crude petroleum, petroleum gas or gold. Conversely, East Asian and some Southern Asian economies have a very high ImpGini, because they import a large amount of primary goods with high PGI values, such as crude petroleum, iron, and food. Finally, Western European economies also have lower ImgGini than most other regions (except Central Asia), due to a large share of low PGI imports from other European economies.

Next, we analyze differences and similarities across countries from different regions. For this purpose, we analyze the scatterplot of the 116 countries' XGinis and ImpGini values between 1990 and 2010 (see Fig. 3). One important observation is that there is no clear correlation between XGinis and ImpGinis. Thus, it cannot be generalized that countries with lower XGini values tend to have higher ImpGini values, or vice versa. There is rather a trend that 

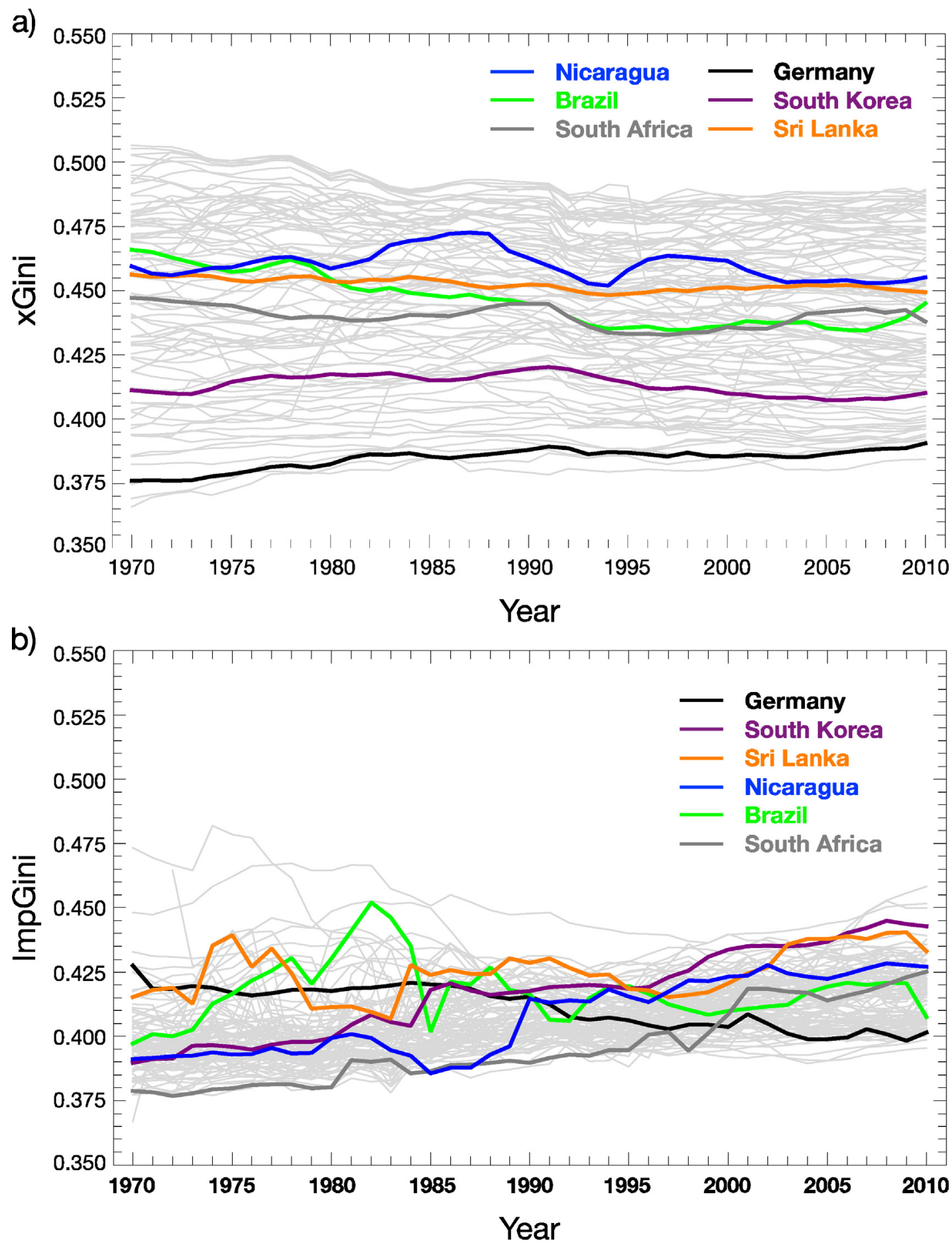

Fig. 4. The evolution of (a) XGinis and (b) ImpGinis between 1970 and 2010.

countries that have both low XGinis and low ImpGini tend to be highly developed, and that countries that have both high XGini and ImpGinis tend to be less developed. By applying a K-means algorithm (Jain, 2010) we can group the 116 countries into 6 clusters with low, medium or high XGini and ImpGini values. The K-means algorithm clusters 


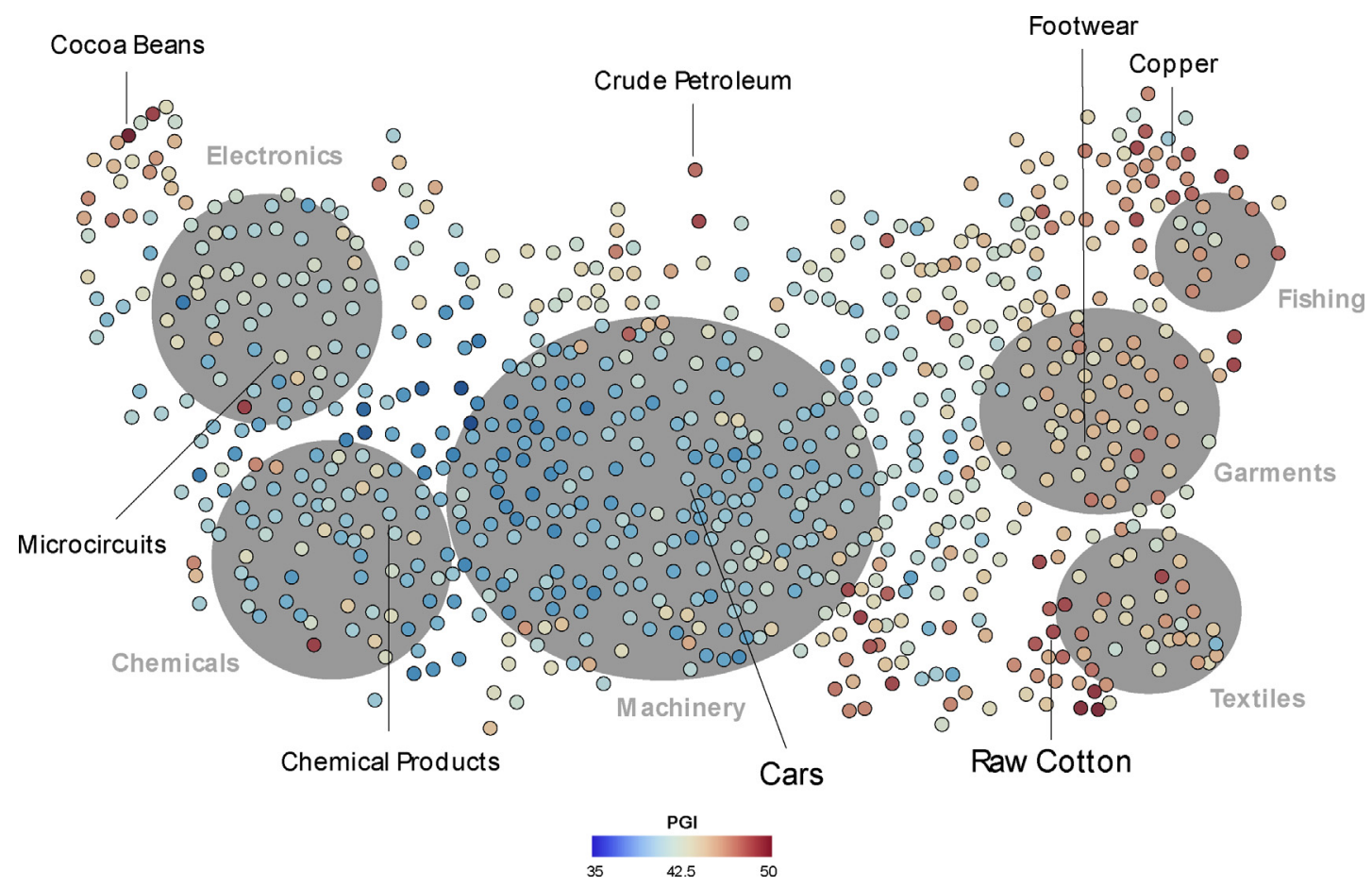

Fig. 5. The Product Gini Space. In this visualization of the product space, nodes are colored according to a product's PGI as measured between 2000 and 2008. The network is based on a proximity matrix representing 766 SITC-4 products classes exported between 1963 and 2008 . The link strength (proximity) is based on the conditional probability that the products are co-exported.

elements in a $\mathrm{n}$-dimensional space by finding the position of $\mathrm{k}$ centroids that minimize the distance to the data-points (Jain, 2010).

On the left bottom of Fig. 3 can observe a green colored cluster of countries with both low XGini and ImpGini values. This green cluster comprises mainly countries from Western and Northern Europe, such as France, Germany, and Sweden, but also some other highly industrialized countries such as Canada or Mexico ${ }^{1}$. On the right next to the green cluster is an orange cluster with (relatively) low XGini and intermediate ImpGini values. This cluster is comprised of countries, such as the US, Spain or Brazil. On the right side of Fig. 3 is a blue cluster of countries with very high ImpGinis and low to intermediate XGinis, comprised by Eastern and Southern Asian economies, such as Japan and South Korea, but also India and Bangladesh. These countries have a very high ImpGini, because they import a large amount of primary high PGI products, such as crude petroleum and agricultural products. On the left top of the ImpGini - XGini scatterplot are red and purple clusters with a high XGinis and low to low ImpGini values. These two clusters are mainly comprised of countries that export crude petroleum, petroleum gas or minerals. The countries of the red cluster, such as Russia, Norway, of Argentina, though are also able to export some products with lower PGI products, whereas the countries of the purple group, such as Iran, Saudi Arabia, Venezuela, Nigeria, Yemen, or Ecuador almost exclusively export crude petroleum or other primary products. Both in the case of the red and purple groups, the income from crude petroleum and other minerals requires them to buy complex low PGI products for their extractive activities, and also allows (at least) parts of its population to buy low inequality products, such as cars. In consequence, they have (relatively) low ImpGini values. Finally, there is a gray cluster of mainly poor economies with both relatively high XGini and ImpGini values, such as Namibia, Morocco, Peru or Nicaragua.

\footnotetext{
1 As a caveat, it must be noted that Mexico's high export and import sophistication, and thus respective high XGini and low ImpGinis, is partially distorted by its maquiladora production for its close neighbor USA. In consequence, its XGini and ImpGini values are likely to be undervalued.
} 
Sri Lanka in 2010

Exports with Revealed Comparative Advantage

Imports with Revealed Comparative Advantage

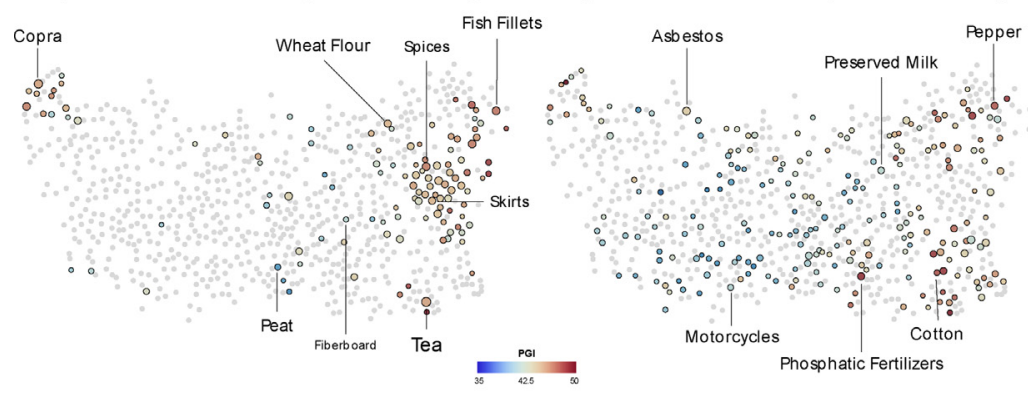

Brazil in 2010

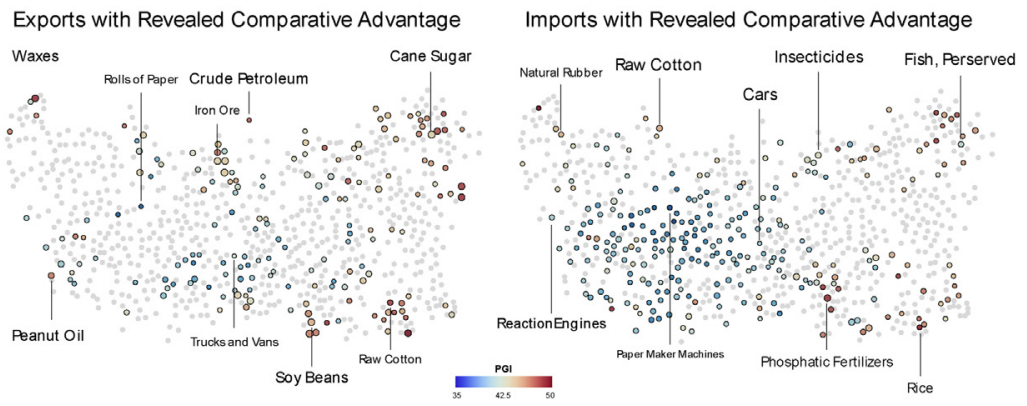

South Korea in $\mathbf{2 0 1 0}$

Exports with Revealed Comparative Advantage Imports with Revealed Comparative Advantage

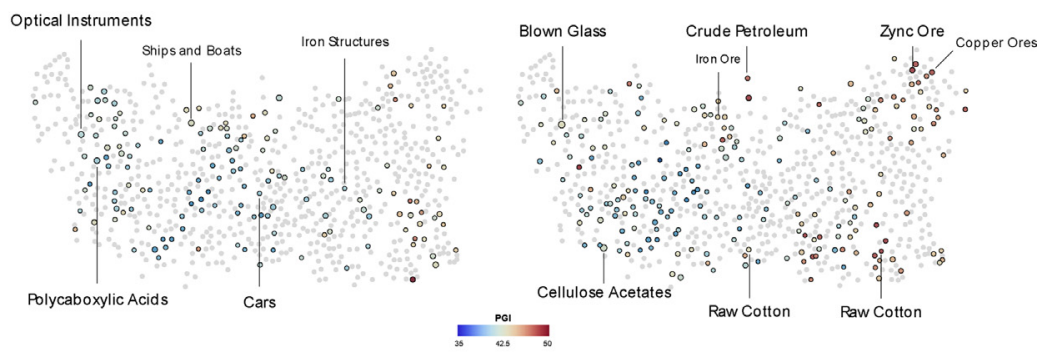

Germany in 2010

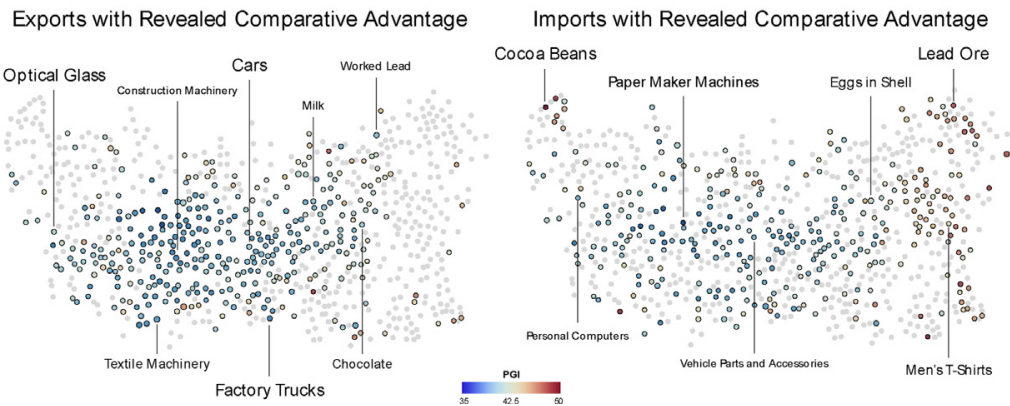

Fig. 6. The XGini and ImpGini Product Spaces of (a) Sri Lanka, (b) Brazil, (c) South Korea, and (d) Germany in 2010. Each node represents a SITC-4 product and is colored according to its PGI value. 


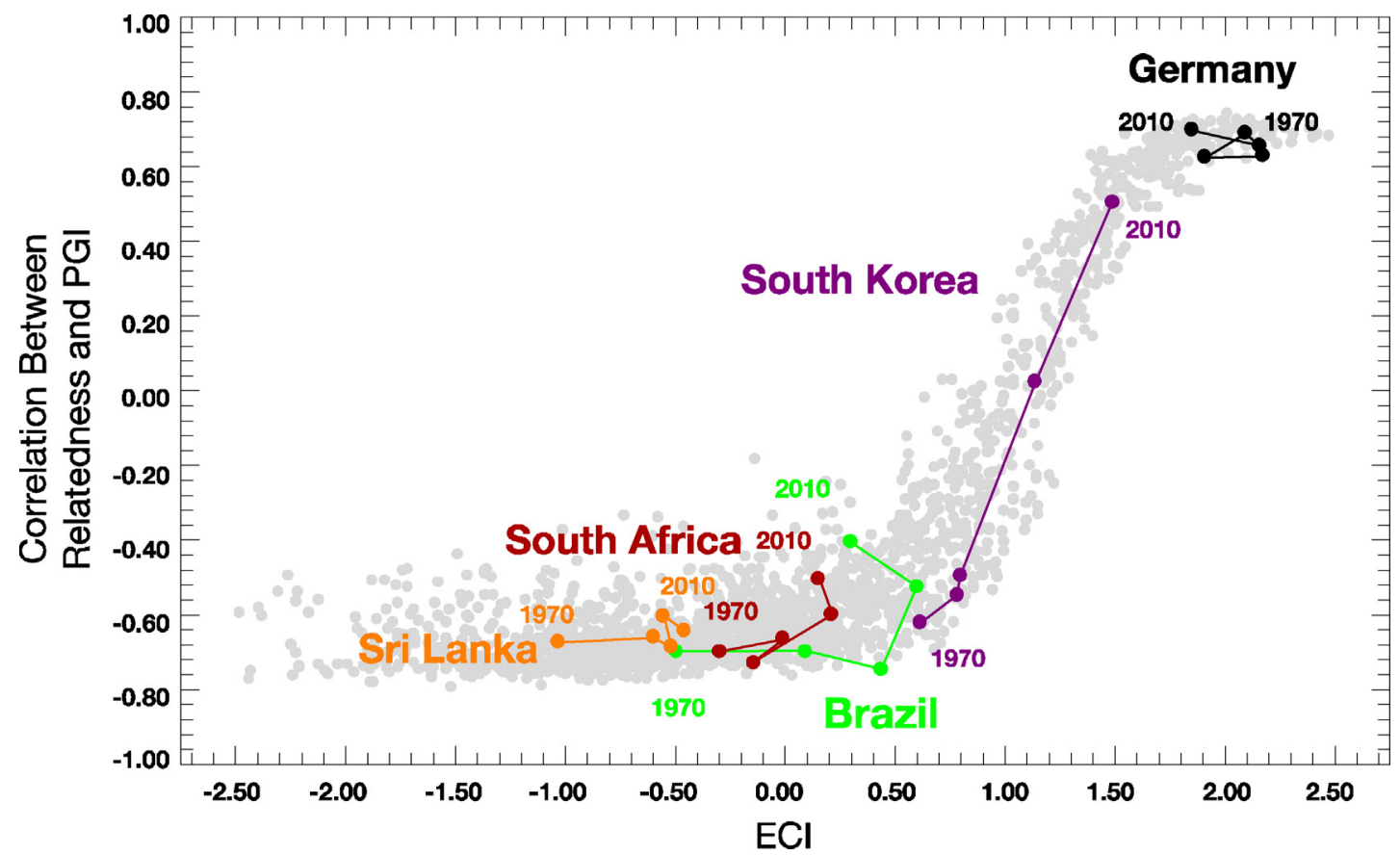

Fig. 7. The stage of economic development and closeness to low PGI products. Each node represents a country in the time periods 1970,1980 , 1990, 2000, and 2010, the position of the nodes depends on their Economic Complexity Index (ECI) and their closeness to low PGI products.

\subsection{The evolution of XGinis and ImpGinis}

In this section, we analyze the evolution of the 116 countries' XGinis and the ImpGinis in the period between 1970 and 2010. We can observe that the XGini values slightly converged in this period in which several developed economies outsourced parts of their production and several developing and emerging economies diversified into more advanced products, such as textiles, metal products or manufactures. However, despite the slight convergence in absolute values, the XGini ranking remained remarkably stable (see Fig. 4a). Only a few countries, such as Turkey, the Philippines, and Tunisia, countries significantly moved up the XGini ranking due to significant industrialization and economic catch-up processes, and only a few countries, such as Norway, Zimbabwe or Congo saw a significant deterioration of their XGini ranking position due to a "resource curse" related to crude petroleum, gold fever, or war, respectively. Still the top of the XGini ranking is dominant by Northern and Western European economies, such as Germany, France, the UK, Denmark, or Sweden, while the bottom of the XGini ranking is dominated by African and Arab countries, such as Nigeria, Ghana, Iran or Qatar that are strongly dependent on the export of crude petroleum or simple agricultural products (See Fig. A3a in the Appendix).

The ImpGinis values and rankings were significantly less stable (Fig. 4b). Most economies saw a significant increase of their ImpGini values in the time between 1970 and 2010. The main reason for this trend is the global export and import of primary products associated with high PGIs, such as crude petroleum, minerals, or tropical fruits, significantly increased in this period. However, some economies, like Japan, saw a significant decline in their previously extremely high ImpGinis. Additionally, we can observe a large level of fluctuation in the ranking positions (see Fig. A3b in the Appendix). There are several reasons for this. Most importantly, the differences in the import portfolios of the countries around the world are significantly smaller than the differences in their export portfolios. While not all countries are able to export manufactured goods, most countries import both manufactured and primary goods. In consequence, small changes frequently led to significant changes in the ranking position. Yet there are also some clear, though heterogeneous, trends across countries. For instance, the ImpGini ranking position of Germany significantly increased between 1970 and 2010. This is arguably due to the establishment of more complex value chains across Europe and thus a higher amount of low PGI products from other European economies. Indeed, several Western and Northern European economies, such as Germany, France, and the UK, featured among the countries with the greatest upward 
movement in the ImpGini ranking (toward lower ImpGinis). Conversely, the ImpGini ranking position of South Korea significantly decreased between 1970 and 2010. This is arguably the case because South Korea outsourced many simple and high PGI products, such as textiles and agricultural products, and its economic growth model is dependent on the import of high PGI products, such as crude petroleum and other natural resources. Among the economies with the largest downwards movements in the ImpGini ranking, feature also South Africa, Pakistan, and Greece, which also saw a large increase in crude petroleum and other primary product imports.

It must be noted that the import portfolios, and thus the ImpGini values of countries, strongly depend on their natural resource endowments, trade unions (such as in the case of Europe) as well as the embeddedness in global value chains. Among the countries with the lowest ImpGinis ranking position in 2010 were both (1) several natural resource-rich countries, such as Argentina or Saudi Arabia, countries that need to import many low PGI products (such as machinery or cars), as well as (2) several highly industrialized countries from Europe, which trade many low PGI products among themselves. At the bottom ImpGini ranking in 2010 featured both (1) industrialized Eastern Asian economies, such as Japan and South Korea - that outsourced low PGI products and depend on the importation of food, crude petroleum and natural resources - as well as (2) developing countries from Africa and Asia, such as Sri Lanka or Côte d'Ivoire, that needed to import basic products and have a lower demand and acquisitive power for manufactured goods (see Fig. A3 in the Appendix).

\subsection{The structural developmental trap of being close to high PGI products}

Next, we use the PGI values in combination with the product space to reveal the structural constraints that developing and emerging economies face in moving into production and export of lower PGI products. The product space is a network that estimates the shared productive capabilities, and thus also knowledge similarity, required to produce two different trade products. It accomplishes this by measuring the conditional probability of a country co-exporting two products (Hidalgo et al., 2007; Hausmann et al., 2014). For instance, countries that are able to export cars are also likely to have the capabilities to export trucks, while exporting cars do not necessarily provide countries with the capabilities to export computer parts. Thus, similar products imply similar productive capabilities, and therefore similar types of human capital, technology, and institutions. Dissimilar products, on the contrary, have significantly different productive capabilities. Fig. 5 illustrates the Product Space with each node representing a SITC trade product that is colored according to its PGI value (Hartmann et al., 2017). We can observe that the products in the core center and left of the product space have significantly lower PGI values than products in the periphery and on the right side of the product space.

Examining the XGini and ImpGini Product Space of very poor and unequal countries, such as Sri Lanka or Nicaragua, reveals that they export products the periphery of the product space, with high PGIs, and import a wide variety of products from all across the product space, including basic products. For instance, Sri Lanka strongly focuses on the export of textile products as well as some simple agricultural products, such as tea and spices (Fig. 6a). Its productive structure is far away from low inequality products in the center of the product space. This puts severe structural constraints on Sri Lanka's ability for inclusive growth because moving into distant parts of the product space is very difficult. As an example, moving competitively into the car industry would require Sri Lanka to build up capabilities in a varied set of technological and economic activities associated with competitiveness in the car industry such as metal products, car components, glass, electronics and so forth. Moreover, a look at the ImpGini Product Space shows that Sri Lanka imports a wide variety of products, including a relatively large share of basic products associated with high levels of inequality. Sri Lanka is a case that shows how the lack of embeddedness into more complex global value chains leads to a lack of (specialization in certain types of) manufactured imports. Moreover, as Sri Lanka does not produce more complex and low inequality products itself, it also has a very limited absorptive capacity to learn from these types of products and what may be necessary to build them.

Next, we examine the XGini and ImpGini Space of countries that face the middle-income trap. The economies of countries, like Brazil or South Africa have been historically based on their resource richness and the exploitation of cheap labor. They have managed to diversify their economies to a certain extent into a varied set of primary products and some manufacturing activities, yet face problems making the transition from an economic development model based on cheap labor towards an economic development model based on knowledge, collective learning, and innovation.

Due to its (relatively) large internal market, Brazil has been partially successful with state-driven industrialization processes and the attraction of some foreign direct investment. Some Brazilian companies have managed to produce 
complex products with lower PGIs, such as airplanes. Moreover, several foreign companies also produce industrial goods in Brazil. Nonetheless, the largest share of its exports is still based on resource-based products that are associated with high levels of inequality, such as iron ore or soybeans (see Fig. 6b). Due to its vast natural resource richness, its XGini Product Space has a "gravitational force" towards specialization on high PGI products in agriculture and mining in the periphery of the product space. This gravitational force is further aggravated in recent years by the rising demand of China and other Asian economies for Brazil's commodities and the competition the same countries impose for the attraction of FDI in more advanced industries (Estevadeordal et al., 2016).

A look at the import portfolio shows how most of Brazil's imports are low PGI chemical and manufacturing products. Brazil produces many intermediate to high PGI products, such as agricultural products, textile or simple metal products internally and thus does not need to import them. In sum, Brazil focuses on the production and export of high PGI products and imports low PGI products.

The XGini and ImpGini Spaces of several East Asian economies, such as Japan and South Korea, reveal a substantially different picture as they have successfully managed to catch-up and leapfrog ahead in advanced economic activities. For instance, South Korea's exports in 2010 are mainly comprised of electronics and manufacturing products with low to intermediate PGI values (Fig. 6c). Among its import portfolio are low PGI imports in chemical, electronics and some manufacturing industries, as well as high PGI imports in the form of several types of commodities. It must be noted that South Korea and several other East Asian, and now increasingly South Eastern Asian economies, experienced a profound transformation of their productive structure. For instance, in 1970 a large percentage of South Korea's export consisted of high PGI textile products, today they outsourced many high PGI products and focus instead almost exclusively on high PGI products. To achieve this, they smartly combined industrial and social policies (Wade, 1990; Stiglitz, 1996; Amsden, 1992; Hartmann et al., 2016). For instance, they deliberately invested in education and skills that are required in the new industries, such as engineering. It is noteworthy that countries learn from their neighbors (Bahar et al., 2014); especially several (East) Asian economies seem to learn from their neighbors how to transform their economies into more complex products. First Japan, then the Tiger States, then China and now several others have moved or are in the process of moving into more advanced industries.

Finally, highly developed economies in Europe, such as Germany, Sweden or Switzerland, almost exclusively focus on the export of low PGI products in manufacturing and chemical products. For instance, Germany has revealed comparative advantages (RCA) in virtually all chemical and manufacturing products, and virtually no RCA in high PGI products (see Fig. 6d). Moreover, it also imports a large number of low PGI products, especially from other European economies, both in terms of inputs in complex value chains as well as end consumer. Most of its textile and commodities imports come from developing or middle-income countries. Having said this, it must be noted that once Germany was also a catch-up economy in the industrialization led by the UK; it focused at some point on textile industries, before becoming one of the leading economies in terms of chemical and manufacturing products.

\subsection{Stage of economic development and the closeness to low PGI products}

Next, we analyze the distance of the 116 countries' export portfolio to low PGI products, and how this distance changed during their process of economic development in the period between 1970 and 2010. To capture the distance to low PGI products, we measure the Pearson correlation between the measured density $\left(\omega_{c p}\right)$ of products without revealed comparative advantage in country $c$ and the PGI values of these products. A positive correlation implies that countries are close to low PGI products, a negative correlation indicates that a country is close to high PGI products.

Fig. 7 shows that until reaching an intermediate to high level of economic development-as measured by economic complexity - countries are relatively close to products that are associated with high levels of inequality. Only a few countries, such as South Korea, were able to move up the ladder towards low PGI products, as produced by highly developed economies like Germany. Instead, most middle-income countries such as South Africa and Brazil made some progress in terms of economic diversification, yet they are barely closer to being specialized in low PGI products than poor economies, such as Sri Lanka or Nicaragua. They face great obstacles in moving towards more inclusive and complex parts of the products space. Most "low hanging fruits" were exploited and substantial changes of the productive capabilities would be necessary to climb into more complex and inclusive parts of the product space. At this intermediate stage, there is both a certain gravitational force towards high PGI products, which are close, and major structural obstacles to transform the economy. Profound changes in skills, institutions, infrastructure and productive organization would be necessary to move from the exploitation of natural resources and cheap labor towards a more 
knowledge-based economy based on productivity and innovation (Rhee, 2012; Felipe et al., 2012a,b; Jankowska et al., 2012; Lee, 2013). Most likely this change would also imply creative destruction processes that can change the preexisting power structures and requires workers, employees, and managers to change their skills and competences substantially. This change would also require profound changes in the education system and human capital. Only a few countries, mostly from East Asia, have managed recently to make this profound change based on a combination of industrial, educational, and social policies (Wade, 1990; Stiglitz, 1996; Jankowska et al., 2012). A set of other middle-income countries, such as Brazil and South Africa have strong structural constraints to make this transition towards more inclusive growth into more complex and lower PGI parts of the product space.

\section{Conclusions}

This article illustrated how methods from economic complexity research can be used to explore the complex association between trade and inequality. Analyzing the inequality associated with the trade specializations and flows between 116 countries, allowed us to illustrate that the core-periphery structure of trade is not only be associated with the income inequality between countries, but also within countries. While highly developed countries mainly export products with a low Product Gini Index (PGI) to both developing and developed economies, developing economies mainly export high inequality products to the world.

We also show that the evolution of XGini values of 116 countries was much more stable in the period between 1970 and 2010 than the evolution of the ImpGini values. This is due to the fact that despite some catch-up processes of developing countries in terms of the production of manufactured goods, the total distance in productive capabilities and emphasis on either more or less exploitative parts of the global values is still very large. Yet, the import portfolios of countries depend on a variety of factors, such as trade unions and resource richness, and thus the need for primary products such as food, minerals or crude petroleum. Despite the fluctuations and heterogeneous trends of countries' regarding their ImpGinis, we can identify clusters of similar countries. For instance, there are several oil and other natural resource dependent countries that have a high XGini and a low ImpGini due to their need of importing low PGI inputs, such as valves and pumps, for the extraction and distribution of their natural resources, as well as their demand for consumer goods, such as cars. Moreover, there is a group of East Asian economies, like South Korea or Japan, that export low PGI products, yet also need to import a large amount of high PGI products, such as crude petroleum or minerals to fuel their economic growth model. Moreover, highly developed economies from Europe mainly exchange low PGI product among themselves. Finally, there is a group of developing economies that both mainly export and import intermediate to high PGI products.

Moreover, only a few countries, such as South Korea, have managed to move up the ladder towards high levels of economic complexity and low XGini values. Our analysis of product space dynamics reveals that the transition from an emerging to a developed economy is complicated because after an initial process of diversification middle income and high inequality countries, such as Brazil or South Africa, may find themselves in a development trap consisting in a productive structure that is close high PGI products and distant to low PGI products of the product space. In consequence, these countries face a gravitational force towards high inequality products in the periphery of the product space. Yet, the experience of successful East Asian economies shows that neither closing the markets nor mere state-driven industrialization alone may be the solution to overcome development traps. Instead, concerted action and collective learning between companies, government, and the civil society is necessary to establish prolific systems of innovation and competence building (Lundvall et al., 2011; Lee, 2013; Hartmann, 2014). This includes a deliberate emphasis on both internal capability upgrading as well as external learning through trade and international innovation networks (Pyka et al., 2016). Closing the market alone will not be the solution, because it also means cutting off the pipeline to necessary inputs and a large amount of knowledge. The cases of successful Asian economies have shown that a simultaneous emphasis on state and market forces, industrial and social policies, internal and external learning are necessary to climb up the steep ladder of development (Wade, 1990; Amsden, 1992; Stiglitz, 1996; Lee, 2013).

As a caveat of our analysis, it must be noted that we only analyze the international trade of goods, and not of services. Moreover, we do not know yet how digital technologies may change the structure of the product space and the inequality associated with different types of manufactures. Finally, we do not analyze in this article the impacts of firm size distributions and different institutional and growth regimes on structural transformations and the distribution of income (Boschma and Capone, 2015; Ciarli et al., 2017). Certainly, these will be important lines of inquiry for future research. 
Nonetheless, we showed how new methods from economic complexity help to provide new empirical insights into the complex association between trade and inequality. We were able to illustrate the core-periphery structure of income inequality associated to the international trade specializations in the time period between 1970 and 2010. Moreover, we were able to reveal the structural constraints of middle- income high-inequality countries, such as Brazil or South Africa, to climb up the development ladder towards a more inclusive productive structure.

\section{Conflict of interest}

None.

\section{Acknowledgements}

DH would like to express his gratitude for the financial support of FAPESP (2017/19842-2) as Visiting Scholar at the University of São Paulo, and FLP expresses his gratitude for the support of the MIT Media Lab consortia. We also would like to thank Cesar Hidalgo, Cristian Jara-Figueroa, Miguel Guevara, Mary Kaltenberg, and Jermain Kaminski, for in-depth discussions on the product space, economic complexity, and income inequality. We are grateful for the help of Alex Simoes and Dave Landry with international trade data from the Observatory of Economic Complexity.

\section{Appendix}

Table A1

List of countries belonging to each geographic region.

\begin{tabular}{|c|c|c|c|c|c|}
\hline Region & Country & ISO & Region & Country & ISO \\
\hline Central Asia & Kazakhstan & kaz & South-eastern Asia & Cambodia & $\mathrm{khm}$ \\
\hline Central Asia & Turkmenistan & $\mathrm{tkm}$ & South-eastern Asia & Indonesia & idn \\
\hline Central Asia & Uzbekistan & uzb & South-eastern Asia & Malaysia & mys \\
\hline Eastern Asia & China & chn & South-eastern Asia & Burma & $\mathrm{mmr}$ \\
\hline Eastern Asia & Hong Kong & hkg & South-eastern Asia & Philippines & phl \\
\hline Eastern Asia & Japan & jpn & South-eastern Asia & Singapore & sgp \\
\hline Eastern Asia & North Korea & prk & South-eastern Asia & Thailand & tha \\
\hline Eastern Asia & South Korea & kor & South-eastern Asia & Vietnam & vnm \\
\hline Eastern Europe & Belarus & blr & Southern Asia & Bangladesh & bgd \\
\hline Eastern Europe & Bulgaria & bgr & Southern Asia & India & ind \\
\hline Eastern Europe & Czech Republic & cze & Southern Asia & Iran & irn \\
\hline Eastern Europe & Hungary & hun & Southern Asia & Pakistan & pak \\
\hline Eastern Europe & Moldova & mda & Southern Asia & Sri Lanka & lka \\
\hline Eastern Europe & Poland & pol & Southern Europe & Bosnia and Herzegovina & bih \\
\hline Eastern Europe & Russia & rus & Southern Europe & Croatia & hrv \\
\hline Eastern Europe & Slovakia & svk & Southern Europe & Greece & grc \\
\hline Eastern Europe & Ukraine & $\mathrm{ukr}$ & Southern Europe & Italy & ita \\
\hline Latin America and the Caribbean & Argentina & $\arg$ & Southern Europe & Macedonia & $\mathrm{mkd}$ \\
\hline Latin America and the Caribbean & Bolivia & bol & Southern Europe & Portugal & prt \\
\hline Latin America and the Caribbean & Brazil & bra & Southern Europe & Slovenia & svn \\
\hline Latin America and the Caribbean & Chile & chl & Southern Europe & Spain & esp \\
\hline Latin America and the Caribbean & Colombia & col & Sub-Saharan Africa & Angola & ago \\
\hline Latin America and the Caribbean & Costa Rica & cri & Sub-Saharan Africa & Botswana & bwa \\
\hline Latin America and the Caribbean & Cuba & cub & Sub-Saharan Africa & Cameroon & $\mathrm{cmr}$ \\
\hline Latin America and the Caribbean & Dominican Republic & dom & Sub-Saharan Africa & Republic of the Congo & $\operatorname{cog}$ \\
\hline Latin America and the Caribbean & Ecuador & ecu & Sub-Saharan Africa & IvoryCoast & $\operatorname{civ}$ \\
\hline Latin America and the Caribbean & El Salvador & $\operatorname{slv}$ & Sub-Saharan Africa & Gabon & gab \\
\hline Latin America and the Caribbean & Guatemala & gtm & Sub-Saharan Africa & Ghana & gha \\
\hline Latin America and the Caribbean & Honduras & hnd & Sub-Saharan Africa & Guinea & gin \\
\hline Latin America and the Caribbean & Jamaica & jam & Sub-Saharan Africa & Kenya & ken \\
\hline
\end{tabular}


Table A1 (Continued)

\begin{tabular}{|c|c|c|c|c|c|}
\hline Region & Country & ISO & Region & Country & ISO \\
\hline Latin America and the Caribbean & Mexico & mex & Sub-Saharan Africa & Liberia & lbr \\
\hline Latin America and the Caribbean & Nicaragua & nic & Sub-Saharan Africa & Mauritius & mus \\
\hline Latin America and the Caribbean & Panama & pan & Sub-Saharan Africa & Mozambique & $\mathrm{moz}$ \\
\hline Latin America and the Caribbean & Paraguay & pry & Sub-Saharan Africa & Namibia & nam \\
\hline Latin America and the Caribbean & Peru & per & Sub-Saharan Africa & Nigeria & nga \\
\hline Latin America and the Caribbean & Trinidad and Tobago & tto & Sub-Saharan Africa & South Africa & zaf \\
\hline Latin America and the Caribbean & Uruguay & ury & Sub-Saharan Africa & Tanzania & tza \\
\hline Latin America and the Caribbean & Venezuela & ven & Sub-Saharan Africa & Zambia & $\mathrm{zmb}$ \\
\hline Northern Africa & Algeria & dza & Sub-Saharan Africa & Zimbabwe & zwe \\
\hline Northern Africa & Egypt & egy & Western Asia & Azerbaijan & aze \\
\hline Northern Africa & Libya & lby & Western Asia & Georgia & geo \\
\hline Northern Africa & Morocco & $\operatorname{mar}$ & Western Asia & Israel & isr \\
\hline Northern Africa & Sudan & $\operatorname{sdn}$ & Western Asia & Jordan & jor \\
\hline Northern Africa & Tunisia & tun & Western Asia & Kuwait & kwt \\
\hline Northern America & Canada & can & Western Asia & Lebanon & lbn \\
\hline Northern America & United States & usa & Western Asia & Oman & omn \\
\hline Northern Europe & Denmark & dnk & Western Asia & Qatar & qat \\
\hline Northern Europe & Estonia & est & Western Asia & Saudi Arabia & sau \\
\hline Northern Europe & Finland & fin & Western Asia & Syria & syr \\
\hline Northern Europe & Ireland & irl & Western Asia & Turkey & tur \\
\hline Northern Europe & Latvia & lva & Western Asia & United Arab Emirates & are \\
\hline Northern Europe & Lithuania & ltu & Western Asia & Yemen & yem \\
\hline Northern Europe & Norway & nor & Western Europe & Austria & aut \\
\hline Northern Europe & Sweden & swe & Western Europe & Belgium & bel \\
\hline Northern Europe & United Kingdom & $\mathrm{gbr}$ & Western Europe & France & fra \\
\hline Oceania & Australia & aus & Western Europe & Germany & deu \\
\hline Oceania & New Zealand & nzl & Western Europe & Netherlands & nld \\
\hline Oceania & Papua New Guinea & png & Western Europe & Switzerland & che \\
\hline
\end{tabular}




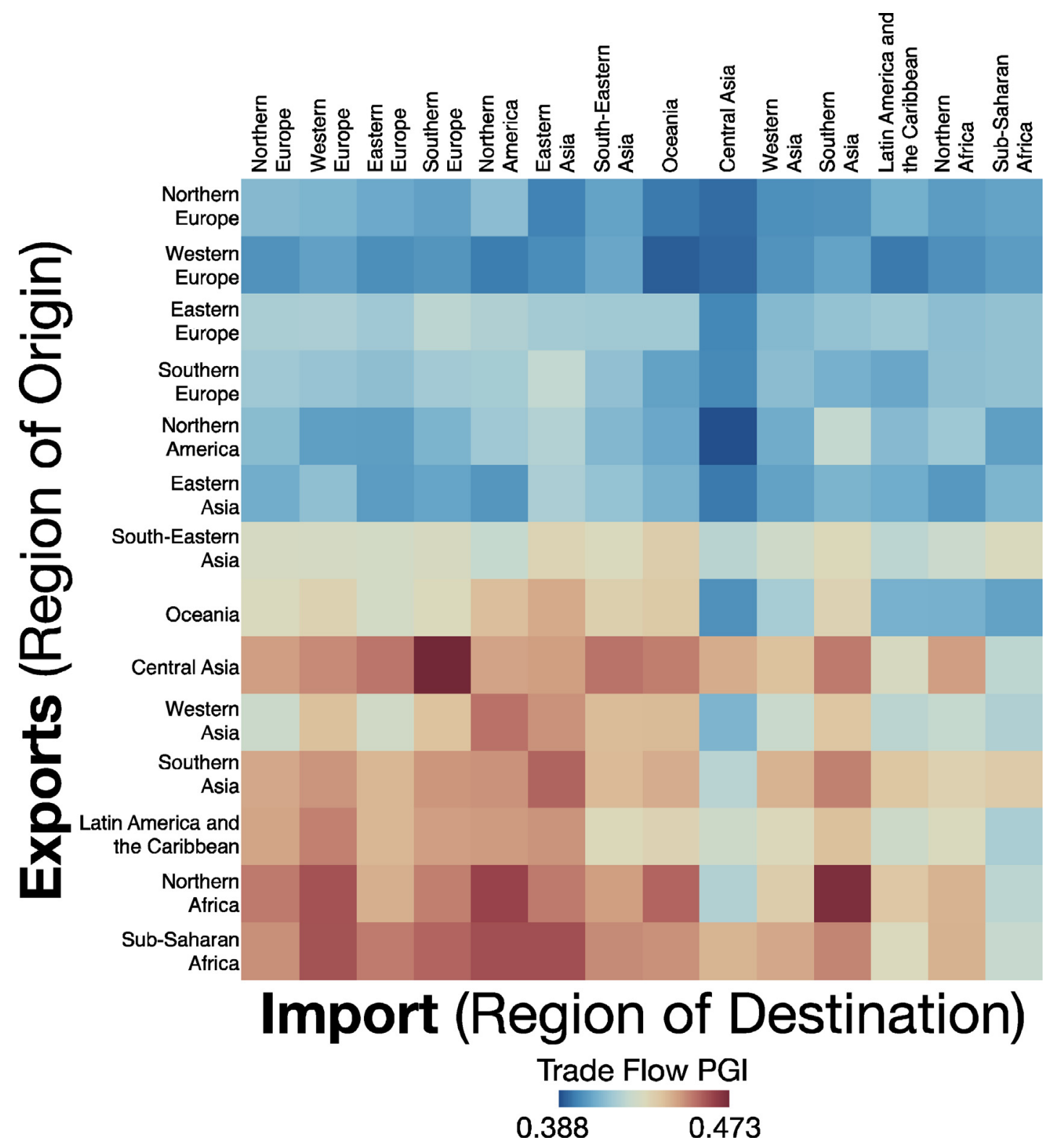

Fig. A1. PGI Bilateral Trade Matrix by geographic region. 


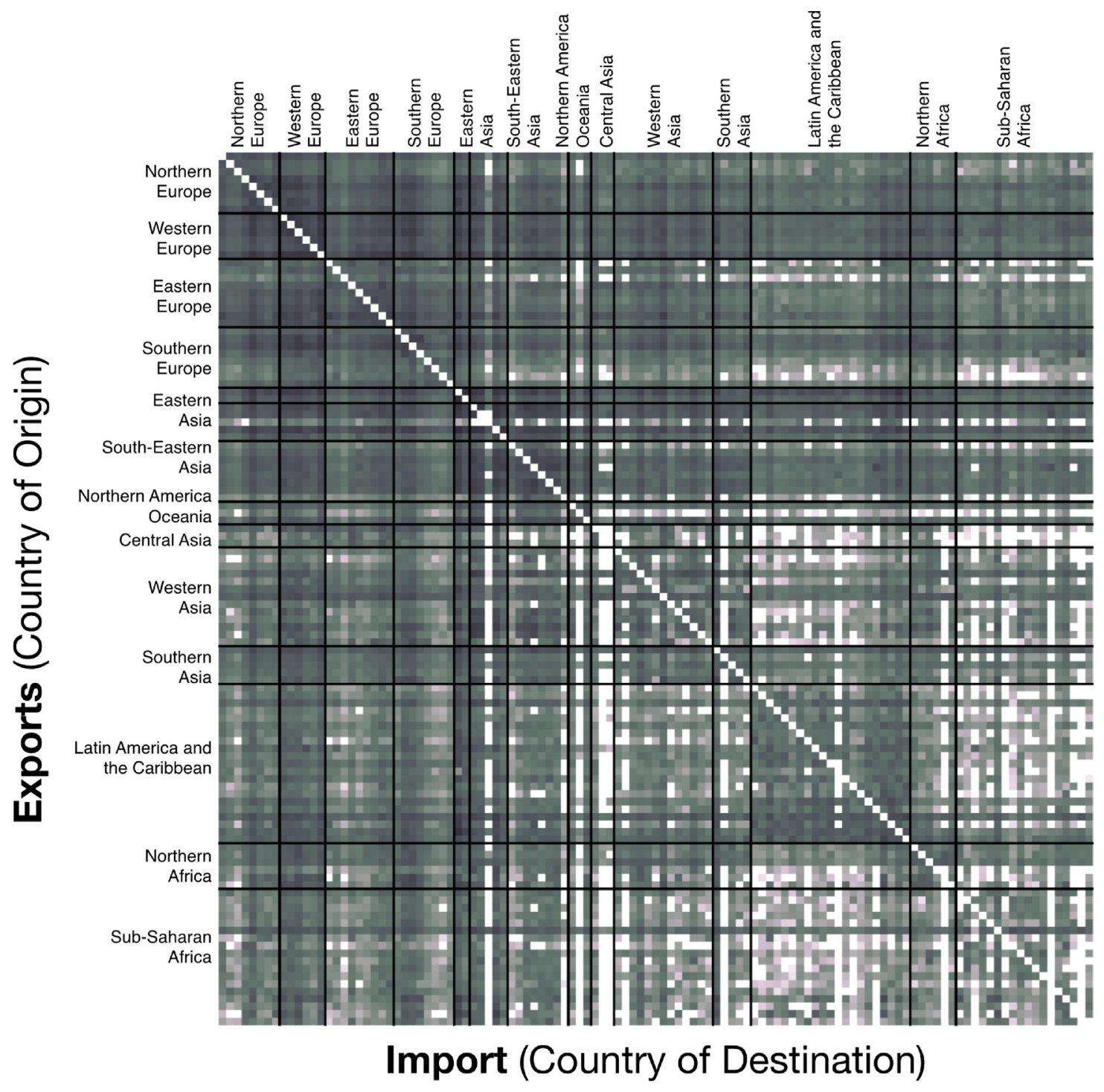

Trade Flow USD $\left(\log _{10}\right)$

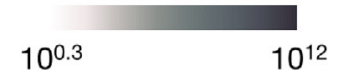

Fig. A2. The size of the bilateral trade between the 116 countries in US \$ in 2010. 
a) Evolution xGini Ranking

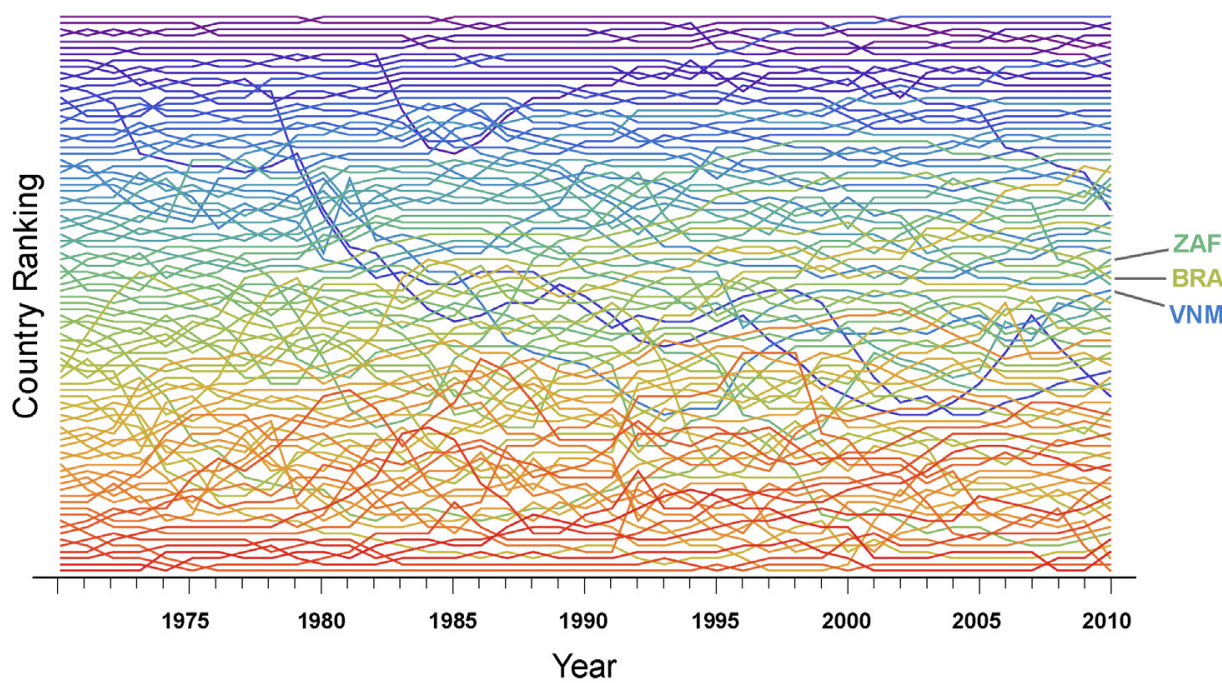

Top 10

Ireland

Denmark

Germany

Finstria

Sweden

France

Hungary

Switzerland

United Kingdom

\section{Bottom 10 \\ Iran \\ Cote d'Ivoire \\ Sudan \\ Rep. of Congo \\ Oman \\ Angola \\ Qatar \\ Cameroon \\ Nigeria \\ Ghana}

b)

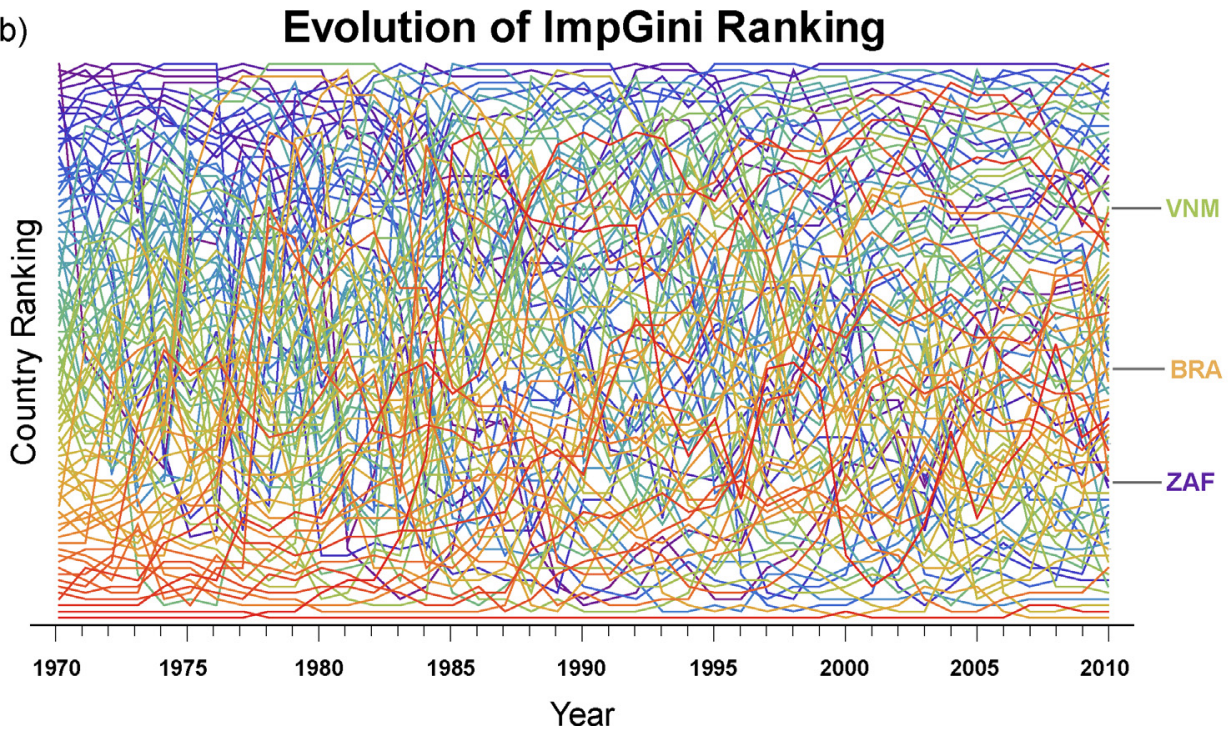

Top 10

Canada

Poland

Germany

Gabon

Argentina

Qatar

Austria

Saudi Arabia

Sweden

Switzerland

\section{Bottom 10}

Zimbabwe

Sri Lanka

Philippines

Pakistan

Cambodia

South Korea

Cote d'Ivoire

Japan

India

Fig. A3. The evolution of (a) XGinis and (b) ImpGinis Ranking between 1970 and 2010.

\section{References}

Acemoglu, D., Robinson, J., 2012. Why Nations Fail: The Origins of Power, Prosperity, and Poverty. Crown, New York.

Alshamsi, A., Pinheiro, F.L., Hidalgo, C.A., 2018. Optimal diversification strategies in the networks of related products and of related research areas. Nat. Commun. 9 (1), 1328.

Amsden, A.H., 1992. Asia's Next Giant: South Korea and Late Industrialization. Oxford University Press on Demand.

Autor, D.H., Dorn, D., Hanson, G.H., 2013. The China syndrome: local labor market effects of import competition in the United States. Am. Econ. Rev. 103 (6), 2121-2168.

Bahar, D., Hausmann, R., Hidalgo, C.A., 2014. Neighbors and the evolution of the comparative advantage of nations: evidence of international knowledge diffusion? J. Int. Econ. 92 (1), 111-123.

Balassa, B., 1965. Trade liberalisation and "revealed" comparative advantage 1. Manchester Sch. 33 (2), 99-123.

Baldwin, R.E., 2008. The Development and Testing of Heckscher-Ohlin Trade Models: A Review. MIT Press.

Balland, P.A., Boschma, R., Crespo, J., Rigby, D.L., 2018. Smart specialization policy in the European Union: relatedness, knowledge complexity and regional diversification. Reg. Stud., 1-17.

Bathelt, H., Malmberg, A., Maskell, P., 2004. Clusters and knowledge: local buzz, global pipelines and the process of knowledge creation. Prog. Hum. Geogr. 28 (1), 31-56. 
Boschma, R., Capone, G., 2015. Institutions and diversification: related versus unrelated diversification in a varieties of capitalism framework. Res. Policy 44 (10), 1902-1914.

Charnovitz, S., 1987. The influence of international labour standards on the world trading regime-A historical overview. Int'1 Lab. Rev. $126,565$.

Ciarli, T., Lorentz, A., Valente, M., Savona, M., 2017. Structural changes and growth regimes. J. Evol. Econ., 1-58.

Cimoli, M., Katz, J., 2003. Structural reforms, technological gaps and economic development: a Latin American perspective. Ind. Corp. Chang. 12 (2), 387-411.

Cimoli, M., Dosi, G., Stiglitz, J.E., 2009. Industrial Policy and Development: The Political Economy of Capabilities Accumulation. Oxford University Press, Oxford, pp. 19-38.

Cimoli, M., Pereima Neto, J.B., Porcile, G., 2015. Cambio Estructural Y Crecimiento. CEPAL, Naciones Unidas.

Collier, P., 2007. The Bottom Billion: Why the Poorest Countries Are Failing and What Can Be Done About It. Oxford University Press, New York.

Cristelli, M., Gabrielli, A., Tacchella, A., Caldarelli, G., Pietronero, L., 2013. Measuring the intangibles: a metrics for the economic complexity of countries and products. PLoS One 8 (8), e70726.

Engerman, S.L., Sokoloff, K.L., 1997. Factor endowments, institutions, and differential paths of growth among new world economies. In: Haber, S.H. (Ed.), How Latin America Fell Behind: Essays on the Economic Histories of Brazil and Mexico, 1800-1914. Stanford Univ. Press, California, pp. 260-304.

Estevadeordal, et al., 2016. Made in CHI-LAT. Keys to renew the convergence between Latin America and China. Integr. Trade J., 40.

Fajnzylber, F., 1990. Industrialization in Latin America: from the 'Black Box' to the 'Empty Box': a comparison of contemporary industrialization patterns. Cuadernos de la CEPAL 60, 1990-08.

Feenstra, R.C., Lipsey, R.E., Deng, H., Ma, A.C., Mo, H., 2005. World Trade Flows: 1962-2000 (Working Paper No. 11040). National Bureau of Economic Research.

Felipe, J., Abdon, A., Kumar, U., 2012a. Tracking the Middle-Income Trap: What is it, Who is in it, and Why? Working Paper Levy Economics Institute, No. 715.

Felipe, J., Kumar, U., Abdon, A., Bacate, M., 2012b. Product complexity and economic development. Struct. Chang. Econ. Dyn. 23 (1), 36-68.

Freeman, C., 1987. Technology Policy and Economic Policy: Lessons From. Pinter, Japan. London.

Frobel, F., Heinrichs, J., Kreye, O., 1976. Tendency towards a new international division of labour: worldwide utilisation of labour force for world market oriented manufacturing. Econ. Polit., 159-170.

Furtado, C., 1959. Formação Econômica Do Brasil. Fundo de Cultura, RJ.

Gala, P., Camargo, J., Freitas, E., 2017. The Economic Commission for Latin America and the Caribbean (ECLAC) was right: scale-free complex networks and core-periphery patterns in world trade. Cambridge J. Econ.

Galbraith, J., Halbach, B., Malinowska, A., Shams, A., Zhang, W., Working Paper No. 68. Retrieved from 2014. UTIP Global Inequality Data Sets 1963-2008: Updates, Revisions and Quality Checks. University of Texas at Austin http://utip.gov.utexas.edu/papers/UTIP_68.pdf.

Gereffi, G., 1999. International trade and industrial upgrading in the apparel commodity chain. J. Int. Econ. 48 (1), 37-70.

Guevara, M., Hartmann, D., Mendoza, M., 2016. “diverse”: diversity measures for complex socioeconomic systems. R J. 8 (2), 60-78.

Hartmann, D., 2014. Economic complexity and human development. In: How Economic Diversification and Social Networks Affect Human Agency and Welfare. Routledge Studies in Development Economics. Routledge, London and New York.

Hartmann, D., Bezerra Hartmann, M., Pinheiro, F., 2018. Identifying Smart Strategies for Economic Diversification and Inclusive Growth in Developing Economies. The Case of Paraguay. World Bank, Mimeo.

Hartmann, D., Guevara, M.R., Jara-Figueroa, C., Aristarán, M., Hidalgo, C.A., 2017. Linking economic complexity, institutions, and income inequality. World Dev. 93, 75-93.

Hartmann, D., Jara-Figueroa, C., Guevara, M., Simoes, A., Hidalgo, C.A., 2016. The structural constraints of income inequality in Latin America. Integr. Trade J. 40, 70-85.

Hausmann, R., Hidalgo, C.A., Bustos, S., Coscia, M., Simoes, A., Yildirim, M.A., 2014. The Atlas of Economic Complexity: Mapping Paths to Prosperity. Mit Press.

Hidalgo, C.A., Hausmann, R., 2009. The building blocks of economic complexity. Proc. Natl. Acad. Sci. 106 (26), 10570-10575.

Hidalgo, C.A., Klinger, B., Barabási, A.L., Hausmann, R., 2007. The product space conditions the development of nations. Science 317 (5837), $482-487$.

Jain, A.K., 2010. Data clustering: 50 years beyond K-means. Pattern Recognit. Lett. 31 (8), 651-666.

Jankowska, A., Nagengast, A., Perea, J.R., OECD Development Centre, Working Paper No. 311 2012. The Product Space and the Middle-Income Trap.

Krueger, A.O., 1985. Import substitution versus export promotion. Finance Dev. 22 (2), 20.

Lee, K., 2013. Schumpeterian Analysis of Economic Catch-Up: Knowledge, Path-Creation, and the Middle-Income Trap. Cambridge University Press.

Lundvall, B.Å., Joseph, K.J., Chaminade, C., Vang, J. (Eds.), 2011. Handbook of Innovation Systems and Developing Countries: Building Domestic Capabilities in a Global Setting. Edward Elgar Publishing.

Macgarvie, M., 2006. Do firms learn from international trade? Rev. Econ. Stat. 88 (1), 46-60.

Martin, W., Maskus, K.E., 2001. Core labor standards and competitiveness: implications for global trade policy. Rev. Int. Econ. 9 (2), $317-328$.

Milanovic, B., 2011. Worlds Apart: Measuring International and Global Inequality. Princeton University Press.

Pinheiro, F.L., Alshamsi, A., Hartmann, D., Boschma, R., Hidalgo, C., arXiv preprint arXiv:1801.05352 2018. Shooting Low or High: Do Countries Benefit From Entering Unrelated Activities?

Prebisch, R., 1962. The economic development of Latin America and its principal problems. Econ. Bull. Lat. Am. 7, 1-12.

Proudman, J., Redding, S., 2000. Evolving patterns of international trade. Rev. Int. Econ. 8 (3), 373-396. 
Pyka, A., Kuştepeli, Y., Hartmann, D. (Eds.), 2016. International Innovation Networks and Knowledge Migration. The German-Turkish nexus, Routledge.

Rhee, C., Published on Asian Development Bank (http://www.adb.org) on March, 27, 2012 2012. Indonesia Risks Falling Into the Middle-Income Trap.

Rodrik, D., 2004. Industrial Policy for the Twenty-First Century.

Rosenstein-Rodan, P.N., 1943. Problems of industrialisation of eastern and south-eastern Europe. Econ. J. 53 (210/211), $202-211$.

Simoes, A.J.G., Hidalgo, C.A., 2011. The economic complexity observatory: an analytical tool for understanding the dynamics of economic development. In: In Scalable Integration of Analytics and Visualization.

Singer, H.W., 1950. The distribution of gains between investing and borrowing countries. Am. Econ. Rev. 40 (2), $473-485$.

Srinivasan, T.N., Bhagwati, J., 2001. Outward-orientation and development: are revisionists right? In: In Trade, Development and Political Economy. Palgrave Macmillan, London, pp. 3-26.

Stiglitz, J.E., 1996. Some lessons from the East Asian miracle. World Bank Res. Obs. 11 (2), 151-177.

Stiglitz, J.E., 2002. Globalization and Its Discontents, 500. Norton, New York.

Stiglitz, J.E., Greenwald, A., Arrow, K., Solow, R., Woodford, M., 2014. Creating a Learning Society: A New Approach to Growth, Development, and Social Progress. Columbia University Press, New York.

Wade, R., 1990. Governing the Market: Economic Theory and the Role of Government in East Asian Industrialization. Princeton University Press. Wallerstein, I.M., 2004. World-Systems Analysis: An Introduction. Duke University Press. 